\title{
Gender Differences in the Pattern of Socio-Demographics Relevant to Metabolic Syndrome Among Kenyan Adults with Central Obesity at a Mission Hospital in Nairobi, Kenya
}

\author{
Okubatsion Tekeste Okube ${ }^{1,2} \cdot$ Samuel T. Kimani ${ }^{2} \cdot$ Waithira Mirie ${ }^{2}$
}

Received: 13 October 2019 / Accepted: 7 January 2020 / Published online: 25 January 2020

(c) Italian Society of Hypertension 2020

\begin{abstract}
Introduction Metabolic syndrome (MetS) is a risk factor for cardiovascular-related morbidity and mortality. Although the risk factors for MetS are well documented, differences in gender-based demographics among Kenyan adults with central obesity are lacking.

Aim Determine gender differences in the pattern of socio-demographics relevant to metabolic syndrome among Kenyan adults with central obesity at a mission hospital, Nairobi.

Methods A cross-sectional baseline survey involving adults $(\mathrm{N}=404)$ with central obesity aged $18-64$ years, as part of a community-based lifestyle intervention study. Respondents were systematically sampled using the International Diabetes Federation definition for MetS. Lifestyle characteristics, anthropometric, clinical and biochemical markers were measured and analyzed using SPSS.

Results High (87.2\%) MetS prevalence associated with advanced age in males $(\mathrm{p}<0.001)$ and females $(\mathrm{p}=0.002)$ was observed. MetS was likely among divorced/separated/widowed $(\mathrm{p}=0.021)$ and high income males $(\mathrm{p}=0.002)$ and females $(p=0.017)$ with high income. Unemployed males $(p=0.008)$ and females with tertiary education $(p=0.019)$ were less likely to have MetS. Advanced age was likely to lead to high blood pressure, fasting blood glucose and triglycerides $(\mathrm{p}<0.05)$. Males were more likely $(\mathrm{p}=0.026)$ to have raised triglycerides, while females $(\mathrm{p}<0.001)$ had low high density lipoproteins. Conclusion A high prevalence of MetS associated with social and gender differences among Kenyan adults with central obesity. These underscore the need to look beyond the behavioral and biological risks and focus on every nuance of gender differences in addressing MetS and CVDs.
\end{abstract}

Keywords Metabolic syndrome $\cdot$ Gender difference $\cdot$ Socio-demographic factors $\cdot$ Anthropometric $\cdot$ Biomarkers $\cdot$ Kenya

\section{Introduction}

The emergent of a global epidemic for non-communicable diseases (NCDs), including hypertension and diabetes points to the need for understanding the role of premorbid states notably metabolic syndrome (MetS). Indeed, MetS has been touted as the main precursor and a leading risk factor for hypertension and diabetes [1-3], conditions contributing

Okubatsion Tekeste Okube

tokube@cuea.edu

1 School of Nursing, The Catholic University of Eastern Africa (CUEA), P.O. Box: 62157-00200, Nairobi, Kenya

2 School of Nursing Sciences, University of Nairobi, Nairobi, Kenya significantly to morbidity and mortality globally. MetS is a constellation of cardiovascular risk factors characterized by central adiposity, hyperglycemia, elevated blood pressure and dyslipidemia [4]. Globally, a quarter of the adult population is estimated to have the syndrome [4]. The prevalence of MetS varies depending on age, sex, and geography similar to cardiovascular diseases (CVDs) with some indications of higher prevalence in females after 50 years relative to men $[5,6]$, while some evidence shows the reverse (Novak et al. 2013). Suffice to say, limited data are depicting MetS prevalence in Kenya. In Kenya, a report estimates the prevalence of MetS to be $34.6 \%$ and was higher in women (40.2\%) than in men (29\%) [7]. Countries like Kenya bear a huge, disproportionate growing burden of CVDs which constitutes a threat to development [8] and realization of full potential. Specifically, MetS-related health burden has 
gained unprecedented momentum in the Sub Saharan Africa due to epidemiological, demographic and nutritional transitions $[9,10]$.

Certainly, individuals with MetS have twice the likelihood of developing and dying from CVDs, and more than seven times the risk of developing diabetes, compared to those without [1-3]. In Kenya, it is estimated that $25 \%$ of hospital admissions and $13 \%$ of deaths are attributed to CVDs, representing the second-highest cause of mortality after infectious/maternal/perinatal causes (Kenya National Guidelines for Cardiovascular Diseases Management 2018). The CVDs are costly to diagnose and manage leading to premature deaths among the most productive individuals in the household and society. Indeed, these conditions are key contributors to poverty associated with high health spending, mostly out-of-pocket because of lack of effective and affordable insurance. The problem, if not addressed, could result in faltering of critical milestones, notably sustainable development goals, national agenda for development and the vision 2030 social development pillars. To nip in the bud the epidemic of CVDs, there is a need for understanding and early identification of MetS and the associated predictors to inform rolling out of preventive interventions.

Evidence demonstrates an inverse relationship between sociodemographic/economic status and CVDs [11-17]. Reduced access to quality health care, lower education status and health literacy, and disparities in health behaviors are believed to be the major contributing factors for CVDs [18]. However, such association is less clear in lower and middle-income countries attributed to paucity of data. A study conducted in Nairobi's slums (Korogocho) showed a high prevalence of overweight and abdominal obesity as well as behavioral risk factors including smoking, alcohol and low vegetables and fruit consumption. In that study, men were more likely to be smokers, abuse alcohol, and have larger waist circumference and higher systolic BP, whereas; women were more likely to have higher BMI. However, there was no significant difference in physical activity and daily fruit and vegetable intake between genders [19]. Generally, those in low-income brackets are more likely to be affected by MetS and subsequently CVDs due to psycho-social related stresses, violence, exposure to harmful products such as unhealthy diet, informal alcohol, smoking and less access to effective and equitable healthcare services [20].

Additionally, the predictors are differential based on gender for MetS and CVDs markers namely anthropometric, clinical and biochemical parameters. Therefore, beyond the behavioral and biological risk factors, a focus on every nuance of gender concerning MetS and CVDs should be considered. However, the relationship between gender-specific social factors and MetS in Kenyan is poorly understood. Therefore, this study sought to determine gender differences in the pattern of socio-demographics relevant to
MetS among Kenyan adults with central obesity visiting an outpatient clinic in Nairobi.

\section{Methods}

\subsection{Study Settings}

The study was carried out at St. Mary's Mission Hospital in Lang'ata constituency, Nairobi. This is a Christian faith-based hospital focusing on healthcare services to the low-income earners that reside in the surrounding informal settlements (slums) of Kibera, Mukuru-Kwa-Njenga and Kuwinda among others. The Kibera slum is viewed as "the largest and poorest slum in Africa" with an average income of USD 39 per person per month [21]. The hospital offers both inpatient and outpatient services. The inpatient has a bed capacity of 350, with the services spanning from medical, surgical, maternity, pediatric, post-natal, newborn unit, operating theatre, gynecology, and physiotherapy. The outpatient services are offered on $24 \mathrm{~h}$ basis which include: general outpatient care, maternal and child health, diabetic and hypertension, nutrition, dental, eye, pharmacy, laboratory and imaging services, as well as HIV/AIDS prevention, treatment, and care Services. The hypertension-diabetic clinic runs from Monday to Friday attending to about 600 patients monthly. The clinic is run by a team of professionals that comprises physicians, nurses, nutritionists, laboratory technicians, pharmacists, and social workers.

\subsection{Study Design, Sampling Methods, and Respondents}

A descriptive, cross-sectional study design involving adults $(n=404)$ with central obesity aged $18-65$ years. This is baseline survey data of the wider "community-based lifestyle modification intervention for the management and control of MetS project". We considered central obesity (waist circumference $\geq 94 \mathrm{~cm}$ for men and $\geq 80 \mathrm{~cm}$ for women) as the first inclusion criteria to screen for the other components of MetS using the International Diabetes Federation (IDF) criteria, thus all the respondents had central obesity. Pregnant and lactating women, as well as those with a serious illness such as cancer, cardiovascular events, mental illness, physical disability or end-stage kidney disease, were excluded from the study. Systematic random sampling was used to select the study respondents. Of the respondents, $(37.4 \%$, $\mathrm{n}=151$ ) were known hypertensive/diabetes patients. During the study period, a monthly average of 600 hypertensive-diabetic patients attended the clinic. This translated to 1800 patients in three months, the duration the baseline survey would take to complete. Accordingly, the sampling interval was determined by dividing the target population 
(1800) per 3 months, by the estimated sample size (151) to get the sample interval of 12 . Thus, every 12 th hypertensivediabetic patient was included in the study until the desired sample size was achieved. Additionally, 253 participants were screened from the laboratory waiting bay using systematic random sampling with resultant inclusion of both patients and the relatives/friends who accompanied the clients. The inclusion of the accompanying person was based on the role of genetic predisposition as well as the environment on CVDs.

\subsection{Data Collection Tools and Procedures}

Two research assistants with a bachelor's degree in Nursing were trained to collect the data and ethical conduct of research. Two experienced laboratory technicians were trained on ethical conduct of research and thereafter involved in obtaining blood samples for biochemical analysis. A pretested, structured questionnaire modified from the WHO Steps Approach for NCDs evaluation was used to assess the socio-demographic variables, disease profile and lifestyle characteristics. Anthropometric measurements (weight, height, body mass index, waist and hip circumference) were collected using standard measurements and procedures. The questionnaire had four sections. The first section was used to collect socio-demographic information. The second was used to collect information on dietary intake patterns. The third section was used to collect clinical and anthropometric parameters using standard measurement. The final section of the questionnaire was used to collect biochemical markers including triglycerides (TGs), high-density lipoprotein cholesterol (HDL-C) and fasting blood glucose.

\subsubsection{Procedures of Anthropometric Measurement}

The respondents' height, weight, waist circumference (WC) and hip circumference (HC) were obtained by two trained research assistants using standard protocols and techniques. Bodyweight was measured to the nearest $0.1 \mathrm{~kg}$ using a Sohenle mechanical weighing scale in a respondent on light clothing. Height (in meters) was measured using a portable stadiometer, with subjects standing upright on a flat surface without shoes, the back of the heels and the occiput on the stadiometer to the nearest $0.5 \mathrm{~cm}$. BMI was calculated as the ratio of weight in kilograms over height in meters squared [weight $(\mathrm{kg}) /$ height $\left(\mathrm{m}^{2}\right)$ ]. WC was taken at the midpoint between the lower margin of the last palpable rib and the top of the iliac crest (hip bone) [22]. WC $\geq 94 \mathrm{~cm}$ for men and $\geq 80 \mathrm{~cm}$ for women was considered as central obesity. $\mathrm{HC}$ was taken around the maximum circumference of the buttocks to the nearest mm using a flexible tape [23]. Waist/ hip ratio (WHR) was calculated by dividing WC by HC. Men with WHR $<0.90,0.90-0.99$ and $\geq 1.0$ were classified as normal weight, overweight and obese respectively, while for women, WHR was classified as $<0.80,0.80-0.84$ and $\geq 0.85$ as normal weight, overweight and obese, respectively.

\subsubsection{Clinical assessment}

Blood pressure (BP) measurement: This involved calling individual respondents into a room and allowing them to seat quietly for 5-10 min to alley anxiety and restlessness. The BP was measured in sitting position on the right arm, using a standard mercury sphygmomanometer with appropriate adult cuff size $(15 \times 33 \mathrm{~cm})$. Two readings of $\mathrm{BP}$, at 5 min' interval were taken from each respondent. Elevated BP was defined as $\geq 130 / 85 \mathrm{mmHg}$ [22]. Prehypertension and hypertension were defined as systolic BP of 120-139 and $\geq 140 \mathrm{mmHg}$ and/or diastolic BP of 80-89 and $\geq 90 \mathrm{mmHg}$, respectively. Subjects with systolic BP and diastolic BP under the defined limits but who reported taking antihypertensive treatment for at least two weeks before the survey were classified as having hypertension [24]. Heart rate: This was measured for $1 \mathrm{~min}$ by placing the index and middle fingers together on the radial artery of the participants' wrist.

\subsubsection{Biochemical Measurements}

Blood samples for respondents who had fasted for $8-12 \mathrm{~h}$ were collected and analyzed by two qualified and experienced laboratory technicians. A sample of $3 \mathrm{~mL}$ of blood was obtained from the brachial vein from each participant by following standard infection prevention procedures. The sample was labeled with the unique participant number and was used to determine triglycerides (TGs) and highdensity lipoprotein cholesterol (HDL-C). Fasting blood glucose (FBG) sample was obtained from the respondents' finger using $\mathrm{HemoCue}{ }^{\circledR} \mathrm{B}$-Glucose photometer (photometer, 1995). Raised FBG was defined as $\geq 5.6 \mathrm{mmol} / \mathrm{L}$ [25], prediabetes, and diabetes were defined as FBG levels: 5.6-6.9 and $\geq 7 \mathrm{mmol} / \mathrm{L}$, respectively [26].

\subsection{Validity and Reliability of the Study Tools}

The validity of the questionnaires was determined by an expert in the field of CVD research who provided feedback to the researchers. The recommendations and suggestions were incorporated into the final questionnaire. A test-re-test method was used to test the reliability of the measurement tools in producing the same results. Moreover, data were collected by two qualified nurses who were trained on the study tools and procedures. The study tools were pretested at Mbagathi hospital, a county referral hospital in Nairobi with a sample of 18 adults ( $5 \%$ of the sample size) with similar characteristics to the actual study population. Both 
St. Mary's Mission Hospital and Mbagathi hospital serve the low-income communities from the surrounding slums of Kibera, Mukuru-Kwa-Njenga, and Kuwinda. The results were analyzed and areas of the questionnaire that were found to be deficient were revised and the questionnaire adapted accordingly.

\subsection{Ethical Consideration}

The ethical approval to conduct this study was obtained from Kenyatta National Hospital-University of Nairobi Ethical Review Committee (KNH-UoN ERC) (Approval number: $\mathrm{P} 430.07 / 2017)$. The institutional permission was granted by the administration of the St. Mary's Mission Hospital. Consent was obtained from the study participants prior to data collection. All the collected data remained anonymous and treated strictly confidential to protect the participants' privacy.

\subsection{Definition of Metabolic Syndrome}

In this study, metabolic syndrome is defined using the International Diabetes Federation [25] criteria as follows: One having abdominal obesity (waist circumference of $\geq 94 \mathrm{~cm}$ for men and $\geq 80 \mathrm{~cm}$ women) and at least two of the following criteria; (1) elevated blood pressure (systolic $\mathrm{BP} \geq 130 \mathrm{mmHg}$ or diastolic $\mathrm{BP} \geq 85 \mathrm{mmHg}$ ) or receiving treatment for hypertension, (2) fasting blood glucose $\geq 5.6 \mathrm{mmol} / \mathrm{L}$ or receiving treatment for diabetes, (3) elevated triglycerides $(\geq 1.7 \mathrm{mmol} / \mathrm{L})$ or receiving treatment for elevated triglycerides, low HDL-cholesterol ( $<1.03 \mathrm{mmol} / \mathrm{L}$ in males and $<1.29 \mathrm{mmol} / \mathrm{L}$ in females $)$ or receiving treatment for low HDL-cholesterol.

\subsection{Data Analyses}

The key outcome variables of this study were MetS and its components. The variables of interest included age, gender, educational, occupation, and income status. The completed questionnaires were checked, cleaned and coded before data entry. Computer software, (SPSS Ver. 22) was used to analyze the data. Data were descriptively analyzed into means, proportions and frequency tables. Associations between categorical variables such as gender, education, marital status and the components of metabolic syndrome were tested using a $\chi^{2}$ test, Fisher's Exact test and binary regression, while a students' t test was used to compare the means for age, income, anthropometric and biochemical measurements. A logistic regression analysis was applied to determine the variables independently contributed to the occurrence of metabolic syndrome. The fitness model was also performed to describe the variance and classification of
Mets between the genders. A p-value of less than 0.05 was considered to be significant.

\section{Results}

\subsection{Socio-Demographic Characteristics of the Respondents}

A total of 404 respondents were participated in the crosssectional part of the study. The mean age of the respondents was $42.5 \pm 11.9($ mean \pm SD) with $59.2 \%$ aged between 31 and 50 years. Most respondents were married (76.0\%), females $(54.5 \%)$, protestants $(59.7 \%)$ and self-employed $(52.2 \%)$. Of the respondents, about half (48.8\%) had a secondary level of education, while $45.5 \%$ reported a monthly family income of USD 100-300 (Table 1).

\subsection{Clinical-Anthropometric Characteristics Across Gender of the Respondents}

Of the respondents, $26 \%(n=105)$ and $11.4 \%(n=46)$ were known hypertensive and diabetes respectively. Among the known hypertensive and diabetes, $8.9 \%(n=36)$ had both conditions. Further analysis with independent $t$ test and $\chi^{2}$ test of independence revealed females were more likely $(\mathrm{p}=0.025)$ to have known their hypertensive status compared to the male respondents. The mean age at diagnosis with hypertension $(\mathrm{p}=0.002)$ or diabetes $(\mathrm{p}=0.029)$ was significantly lower in females (43.82 \pm 8.6 years) compared to males $(49.89 \pm 10.5$ years) (mean $\pm \mathrm{SD})$. The respondents mean clinical and anthropometric parameters were as follows: SBP/DBP of $133.45 \pm 18.8 / 85.09 \pm 11.8 \mathrm{mmH}$ $\mathrm{g}$, heart rate of $77.05 \pm 12.8$ beats per minute and fasting blood glucose $(\mathrm{FBG})$ of $4.99 \pm 1.0 \mathrm{mmol} / \mathrm{L}$. The mean waist circumference (WC), hip circumference (HC) and body mass index (BMI) were $99.74 \pm 10.2 \mathrm{~cm}, 109.27 \pm 9.0 \mathrm{~cm}$ and $30.19 \pm 5.0 \mathrm{~cm}$, respectively. Further analysis revealed that males had significantly $(\mathrm{p}<0.001)$ higher mean WC compared to females. Whereas, females had significantly higher mean heart rate $(\mathrm{p}=0.040)$, hip circumference $(\mathrm{cm})$ $(\mathrm{p}<0.001)$, body mass index $(\mathrm{BMI})(\mathrm{p}<0.001)$ and risk of CVDs $(\mathrm{p}<0.001)$ compared to male respondents (Table 2).

\subsection{Relationship between family history of hypertension/diabetes and metabolic syndrome across gender of the respondents}

Of the study respondents, $33.2 \%(n=61)$ males and $38.6 \%$ $(\mathrm{n}=85)$ females had family history of hypertension. Moreover, $20.1 \%(n=37)$ males and $19.5 \%(n=43)$ females had family history of diabetes. Further analysis with a chi-square test of independence revealed the prevalence of metabolic 
Table 1 Socio-demographic characteristics of the respondents

\begin{tabular}{|c|c|c|}
\hline Baseline characteristics & Number (n) & Percent $(\%)$ \\
\hline \multicolumn{3}{|l|}{ Age } \\
\hline$\leq 30$ years & 68 & 16.8 \\
\hline $31-40$ years & 124 & 30.7 \\
\hline $41-50$ years & 115 & 28.5 \\
\hline$>50$ years & 97 & 24.0 \\
\hline \multicolumn{3}{|l|}{ Gender } \\
\hline Male & 184 & 45.5 \\
\hline Female & 220 & 54.5 \\
\hline \multicolumn{3}{|l|}{ Marital status } \\
\hline Married & 307 & 76.0 \\
\hline Single & 69 & 17.1 \\
\hline Divorced & 7 & 1.7 \\
\hline Separated & 11 & 2.7 \\
\hline Widowed & 10 & 2.5 \\
\hline \multicolumn{3}{|l|}{ Religion } \\
\hline Protestant & 241 & 59.7 \\
\hline Catholic & 131 & 32.4 \\
\hline Muslim & 32 & 7.9 \\
\hline \multicolumn{3}{|l|}{ Level of education } \\
\hline No formal education & 7 & 1.7 \\
\hline Primary & 75 & 18.6 \\
\hline Secondary & 197 & 48.8 \\
\hline College/university & 125 & 30.9 \\
\hline \multicolumn{3}{|l|}{ Occupation } \\
\hline Government employee & 15 & 3.7 \\
\hline Non-government employee & 111 & 27.5 \\
\hline Self-employed & 211 & 52.2 \\
\hline Unemployed (able to work) & 39 & 9.7 \\
\hline Unemployed (unable to work) & 21 & 5.2 \\
\hline Doing house work at home & 7 & 1.7 \\
\hline \multicolumn{3}{|l|}{ Family monthly income (USD) } \\
\hline$<100$ & 67 & 16.6 \\
\hline $101-300$ & 184 & 45.5 \\
\hline $301-500$ & 66 & 16.3 \\
\hline Over 500 & 49 & 12.1 \\
\hline No response & 38 & 9.4 \\
\hline Total & 404 & 100.0 \\
\hline
\end{tabular}

syndrome was significantly higher $(\mathrm{p}=0.016)$ among female respondents with a family history of hypertension (Table 3).

\subsection{Relationship Between Family History of Hypertension/Diabetes and Current Blood Pressure and Diabetic Status Across Gender of the Respondents}

Of the respondents, $34.2 \%(n=138)$ and $48.3 \%(n=195)$ were found to be pre-hypertensive and hypertensive (BP $\geq 140 / 90 \mathrm{mmHg}$ ), respectively. Of the hypertensive respondents, $46.2 \%(\mathrm{n}=90)$ were not aware having hypertension. Additionally, $12.1 \%(n=49)$ and $11.6 \%(n=47)$ were pre-diabetic and diabetics, respectively. Further analysis with a chi-square test of independence revealed a significant association between family history of hypertension and blood pressure. Respondents with family history of hypertension were more likely $(\mathrm{p}=0.022)$ in males and $(\mathrm{p}=0.001)$ in females to have hypertension compared to those without history of hypertension. Moreover, respondents with family history of diabetes were more likely $(\mathrm{p}<0.001)$ in males and $(\mathrm{p}<0.001)$ in females to develop diabetes compared to those without history of diabetes (Table 4).

\subsection{Relationship Between Age and Metabolic Syndrome-Related Components Across Gender}

All the respondents had central obesity (WC: $\geq 94 \mathrm{~cm}$ for men, $\geq 80 \mathrm{~cm}$ for women). The overall prevalence of MetS was $87.2 \%$, with no significant difference between the genders $($ female $=87.3 \%$, male $=87 \%, p=0.925$ ). Elevated BP (65.8\%), TGs (64.9\%) and low HDL-C (75.5\%) were the most prevalent Mets-related components among the respondents. Analysis with a chi-square test of independence and Fisher's Exact test revealed a significant association between age and MetS as well as the related components. Irrespective of gender, the prevalence of MetS was significantly higher among those aged above 49 years compared to the rest. Female respondents above 49 years old were more likely to have MetS $(\mathrm{p}<0.001)$, elevated BP $(\mathrm{p}<0.001)$, raised TGs $(p=0.043)$ and raised FBG level $(p<0.001)$ compared to those below or 49 years old. Similarly, male respondents aged above 49 years were more likely to have MetS $(p<0.001)$, elevated BP $(p<0.001)$ and raised FBG level $(\mathrm{p}<0.001)$ compared to those below or 49 years old (Table 5).

\subsection{Relationships Between Marital Status and Metabolic Syndrome-Related Components Across Gender}

Analysis with chi-square test of independence revealed that the divorced/separated/widowed men were more likely $\left(\chi^{2}=18.203, \mathrm{p}<0.001\right)$ to have MetS compared to those who were married. Moreover, irrespective of gender, divorced/separated/widowed respondents were more likely to have elevated BP (males, $\chi^{2}=8.198, \mathrm{p}=0.012$, females, $\chi^{2}=7.211, \mathrm{p}=0.027$ ) and raised FBG level (males, $\chi^{2}=12.535, p=0.001$, females, $\chi^{2}=6.087, p=0.048$ ) compared to the rest. The divorced/separated/widowed female respondents were more likely $\left(\chi^{2}=6.960, p=0.025\right)$ to have reduced HDL-C compared to the married and the never married (single) (Table 6). 
Table 2 Clinical-anthropometric characteristics across gender in the respondents

\begin{tabular}{|c|c|c|c|c|}
\hline General characteristics & $\begin{array}{l}\text { Male } \\
\mathrm{N}(\%)\end{array}$ & $\begin{array}{l}\text { Female } \\
\mathrm{N}(\%)\end{array}$ & $\begin{array}{l}\text { Total } \\
\mathrm{N}(\%)\end{array}$ & $\mathrm{P}$ \\
\hline Respondents, N (\%) & $184(45.5)$ & $220(54.5)$ & $404(100)$ & \\
\hline Mean age in years $( \pm$ SD) & $42.82 \pm 12.6$ & $42.24 \pm 11.3$ & $42.50 \pm 11.9$ & $0.624 *$ \\
\hline Known hypertensive N (\%) & & & & $0.025 * *$ \\
\hline Yes & $38(36.2)$ & $67(63.8)$ & $105(26.0))$ & \\
\hline No & $146(48.8)$ & $153(51.2)$ & $299(74.0)$ & \\
\hline Total & $184(45.5)$ & $220(54.5)$ & $404(100.0)$ & \\
\hline Mean age at diagnosis with hypertension $( \pm \mathrm{SD})$ & $49.89 \pm 10.5$ & $43.82 \pm 8.6$ & $46.04 \pm 9.7$ & $0.002 *$ \\
\hline Family history of hypertension N (\%) & & & & $0.253 * *$ \\
\hline Yes & $61(41.8)$ & $85(58.2)$ & $146(36.1)$ & \\
\hline No & $123(47.7)$ & $135(52.3)$ & $258(63.9)$ & \\
\hline Total & $184(45.5)$ & $220(54.5)$ & $404(100.0)$ & \\
\hline Known diabetes N (\%) & & & & $0.540 * *$ \\
\hline Yes & $19(41.3)$ & $27(58.7)$ & $46(11.4)$ & \\
\hline No & $165(46.1)$ & $193(53.9)$ & $358(88.6)$ & \\
\hline Total & $184(45.5)$ & $220(54.5)$ & $404(100.0)$ & \\
\hline Mean age at diagnosis with diabetes $( \pm \mathrm{SD})$ & $52.58 \pm 11.7$ & $45.81 \pm 8.5$ & $48.61 \pm 10.4$ & $0.029 *$ \\
\hline Family history of diabetes $\mathrm{N}(\%)$ & & & & $0.887 * *$ \\
\hline Yes & $37(46.3)$ & $43(53.7)$ & $80(19.8)$ & \\
\hline No & $147(45.4)$ & 177 (54.6) & $324(80.2$ & \\
\hline Total & $184(45.5)$ & $220(54.5)$ & $404(100.0)$ & \\
\hline Known hypertensive and diabetes, N (\%) & $15(41.7)$ & $21(58.3)$ & $36(8.9)$ & \\
\hline Mean systolic BP $( \pm \mathrm{SD})$ & $134.45 \pm 18.8$ & $132.61 \pm 18.8$ & $133.45 \pm 18.8$ & $0.328^{*}$ \\
\hline Mean diastolic BP $( \pm$ SD $)$ & $84.47 \pm 11.8$ & $85.62 \pm 11.9$ & $85.09 \pm 11.8$ & $0.333^{*}$ \\
\hline Mean heart rate $( \pm S D)$ & $75.62 \pm 12.6$ & $78.24 \pm 12.8$ & $77.05 \pm 12.8$ & $0.040^{*}$ \\
\hline Mean FBG level $( \pm$ SD) & $4.90 \pm 0.9$ & $5.05 \pm 1.1$ & $4.99 \pm 1.0$ & $0.127 *$ \\
\hline Mean waist circumference $( \pm$ SD) & $101.94 \pm 8.5$ & $97.98 \pm 11.1$ & $99.74 \pm 10.2$ & $0.000 *$ \\
\hline Mean hip circumference $( \pm S D)$ & $106.57 \pm 7.2$ & $111.573 \pm 9.6$ & $109.27 \pm 9.0$ & $0.000 *$ \\
\hline Mean waist-hip ratio $( \pm \mathrm{SD})$ & $1.99 \pm 9.9$ & $0.88 \pm 0.1$ & $1.38 \pm 6.7$ & $0.095^{*}$ \\
\hline Mean body mass index $\left(\mathrm{kg} / \mathrm{m}^{2}\right)( \pm \mathrm{SD})$ & $29.20 \pm 5.2$ & $31.02 \pm 4.6$ & $30.19 \pm 5.0$ & $0.000 *$ \\
\hline Waist-hip ratio & & & & $0.000 *$ \\
\hline Low risk ( $\leq 0.95$ for men, $\leq 0.80$ for women) & $100(75.2)$ & $33(24.8)$ & $133(100)$ & \\
\hline Moderate risk ( 0.96 to 1.0 for men, 0.81 to 0.85 for women) & $63(54.3)$ & $53(45.7)$ & $116(100)$ & \\
\hline High risk ( $>1$ for men, $>0.85$ for women) & $21(13.5)$ & $134(86.5)$ & $155(100)$ & \\
\hline
\end{tabular}

*Independent $t$ test

**Chi-square test of independence

\subsection{Relationship Between Educational Attainment and Metabolic Syndrome Across Gender}

Analysis with binary regression revealed an inverse relationship between level of education and MetS in females. Females with tertiary level of education were 34 and 33\% less likely to have MetS (AOR $=0.34 ; 95 \%$ CI $0.14-0.84 ; \mathrm{p}=0.019)$ and raised fasting blood glucose level (AOR $=0.33 ; 95 \%$ CI $0.23-1.96 ; p=0.016$ ) compared to those with primary or secondary education.
Moreover, females with secondary education were more likely $(\mathrm{AOR}=2.62 ; 95 \%$ CI $0.61-10.30 ; \mathrm{p}=0.021)$ to develop elevated blood pressure compared to those with primary or tertiary education. However, males who attained a tertiary level of education were more likely to develop MetS $(\mathrm{AOR}=1.28 ; 95 \%$ CI $0.51-3.20 ; \mathrm{p}=0.598)$ and raised triglycerides $(\mathrm{AOR}=1.92 ; 95 \%$ CI 1.11-3.31; $\mathrm{p}=0.046)$ compared to those with primary or secondary education (Table 7). 
Table 3 Relationship between family history of hypertension/diabetes and metabolic syndrome among the respondents

\begin{tabular}{|c|c|c|c|c|c|c|c|}
\hline \multirow{2}{*}{$\begin{array}{l}\text { Family history of } \\
\text { hypertension }\end{array}$} & \multirow[t]{2}{*}{ Status } & \multicolumn{2}{|c|}{ Metabolic syndrome } & \multirow[t]{2}{*}{ Total (n, \%) } & \multirow[t]{2}{*}{ Chi $\left(\chi^{2}\right)$} & \multirow[t]{2}{*}{ df } & \multirow[t]{2}{*}{$\mathrm{p}$-value } \\
\hline & & No & Yes & & & & \\
\hline \multirow[t]{3}{*}{ Male } & Yes & $6(9.8)$ & $55(90.2)$ & $61(100)$ & 0.828 & 1 & 0.363 \\
\hline & No & $18(14.6)$ & $105(85.4)$ & $123(100)$ & & & \\
\hline & Total & $24(13.0)$ & $160(87.0)$ & $184(100)$ & & & \\
\hline \multirow[t]{3}{*}{ Female } & Yes & $5(5.9)$ & $80(94.1)$ & $85(100)$ & 5.843 & 1 & 0.016 \\
\hline & No & $23(17.0)$ & $112(83.0)$ & $135(100)$ & & & \\
\hline & Total & $28(12.7)$ & $192(87.3)$ & $220(100)$ & & & \\
\hline \multirow{2}{*}{$\begin{array}{l}\text { Family history of } \\
\text { diabetes }\end{array}$} & \multirow[t]{2}{*}{ Status } & \multicolumn{2}{|c|}{ Metabolic syndrome } & Total (n, \%) & Chi $\left(\chi^{2}\right)$ & df & $\mathrm{p}$-value \\
\hline & & No & Yes & & & & \\
\hline \multirow[t]{3}{*}{ Male } & Yes & $4(10.8)$ & $33(89.2)$ & $37(100)$ & 0.204 & 1 & 0.652 \\
\hline & No & $20(13.6)$ & $127(86.4)$ & $147(100)$ & & & \\
\hline & Total & $24(13.0)$ & $160(87.0)$ & $184(100)$ & & & \\
\hline \multirow[t]{3}{*}{ Female } & Yes & $3(7.0)$ & $40(93.0)$ & $43(100)$ & 1.591 & 1 & 0.207 \\
\hline & No & $25(14.1)$ & $152(85.9)$ & $177(100)$ & & & \\
\hline & Total & $28(12.7)$ & $192(87.3)$ & $220(100)$ & & & \\
\hline
\end{tabular}

Table 4 Relationship between family history of hypertension/diabetes and current blood pressure and diabetic status of the respondents

\begin{tabular}{|c|c|c|c|c|c|c|c|}
\hline \multirow{2}{*}{$\begin{array}{l}\text { Family history of } \\
\text { hypertension }\end{array}$} & \multicolumn{3}{|c|}{ Current blood pressure status } & \multirow[t]{2}{*}{ Total $(\mathrm{n}, \%)$} & \multirow[t]{2}{*}{ Chi $\left(\chi^{2}\right)$} & \multirow[t]{2}{*}{$\mathrm{df}$} & \multirow[t]{2}{*}{$\mathrm{p}$-value } \\
\hline & Normal & Prehypertension & Hypertension & & & & \\
\hline \multicolumn{8}{|l|}{ Male } \\
\hline Yes & $8(13.1)$ & 15 (24.6) & $38(62.3)$ & $61(100)$ & 7.658 & 2 & 0.022 \\
\hline No & $25(20.3)$ & $48(39.0)$ & $50(40.7)$ & $123(100)$ & & & \\
\hline Total & 33 (17.9) & $63(34.2)$ & $88(47.8)$ & $184(100)$ & & & \\
\hline \multicolumn{8}{|l|}{ Female } \\
\hline Yes & $8(9.4)$ & $22(25.9)$ & $55(64.7)$ & 85 (100) & 15.048 & 2 & 0.001 \\
\hline No & $30(22.2)$ & $53(39.3)$ & $52(38.5)$ & $135(100)$ & & & \\
\hline Total & $38(17.3)$ & $75(34.1)$ & 107 (48.6) & $220(100)$ & & & \\
\hline \multirow{2}{*}{$\begin{array}{l}\text { Family history of } \\
\text { diabetes }\end{array}$} & \multicolumn{3}{|c|}{ Diabetes status } & Total (n, \%) & Chi $\left(\chi^{2}\right)$ & df & $\mathrm{p}$-value \\
\hline & Normal & Pre-diabetes & Diabetes & & & & \\
\hline \multicolumn{8}{|l|}{ Male } \\
\hline Yes & $20(54.1)$ & $5(13.5)$ & $12(32.4)$ & $37(100)$ & 20.376 & & $0.000^{*}$ \\
\hline No & $122(83.0)$ & $18(12.2)$ & $7(4.8)$ & $147(100)$ & & & \\
\hline Total & $142(77.2)$ & $23(12.5)$ & $19(10.3)$ & $184(100)$ & & & \\
\hline \multicolumn{8}{|l|}{ Female } \\
\hline Yes & $21(48.8)$ & $7(16.3)$ & $15(34.9)$ & $43(100)$ & 26.533 & 2 & 0.000 \\
\hline No & 145 (81.9) & $19(10.7)$ & $13(7.3)$ & $177(100)$ & & & \\
\hline Total & $166(75.5)$ & $26(11.8)$ & $28(12.7)$ & $220(100)$ & & & \\
\hline
\end{tabular}

\subsection{Relationship Between Employment Status and Metabolic Syndrome Across Gender}

The results showed a significant association between employment status and MetS in men but not in women. The prevalence of MetS was higher among employed men compared to the unemployed. Analysis with a chi-square test of independence revealed that self-employed males were more likely $\left(\chi^{2}=6.381, \mathrm{p}=0.016\right)$ to develop MetS compared to the unemployed. Moreover, self-employed females and males were more likely to have elevated BP $\left(\chi^{2}=7.813, \mathrm{p}=0.035\right)$ and raised TGs $\left(\chi^{2}=14.931\right.$, $\mathrm{p}=0.001$ ), respectively (Table 8 ). 


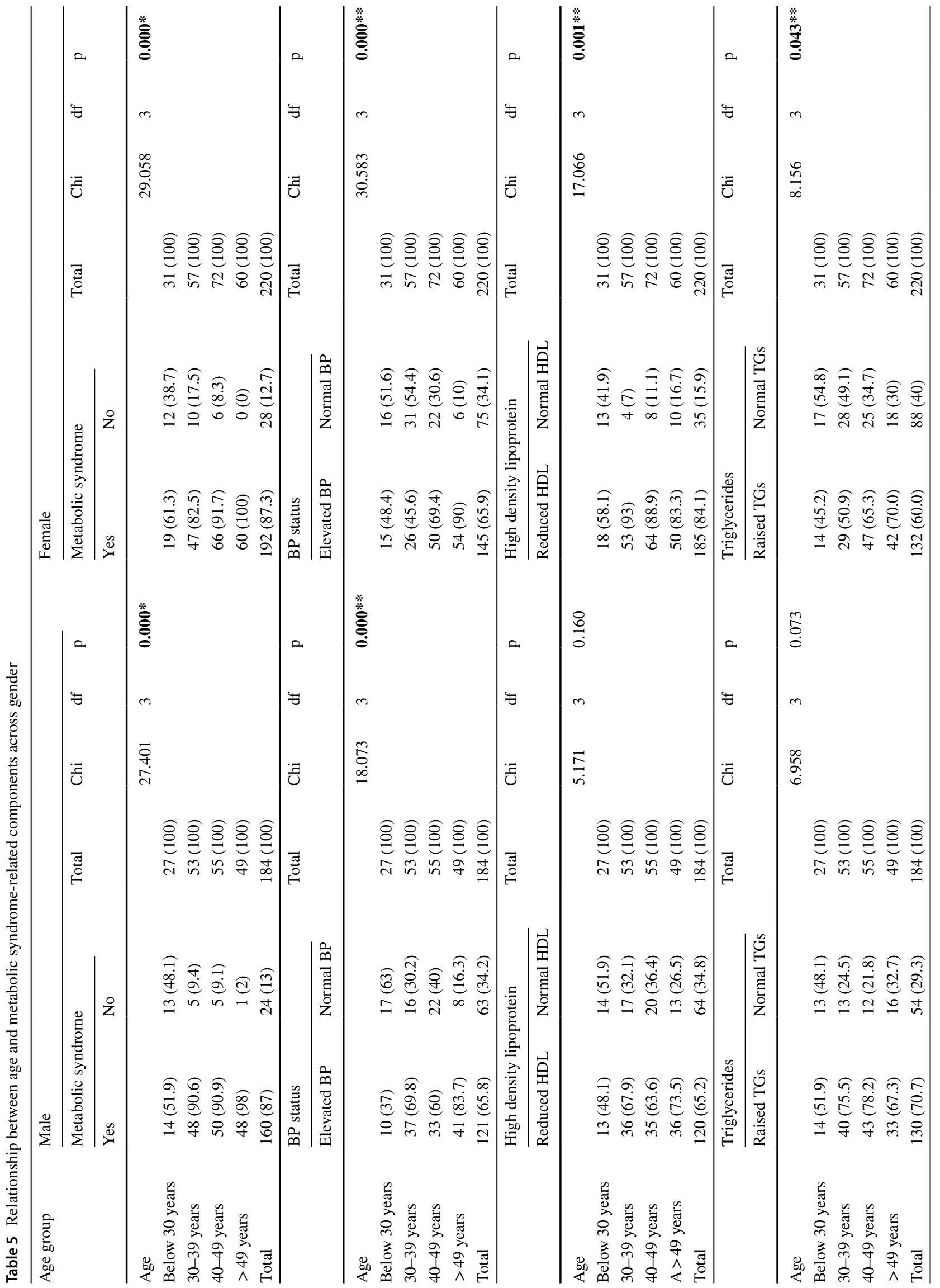




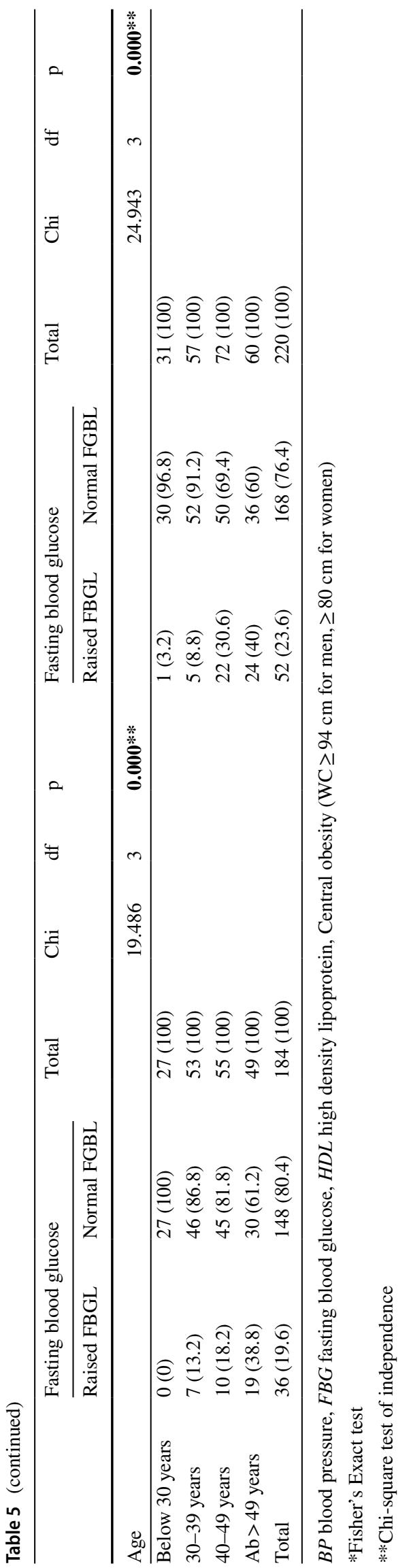

\subsection{Relationship Between Family Income and Metabolic Syndrome-Related Components Across Gender}

Analysis with a chi-square test of independence revealed a significant association between family monthly income and MetS. Male respondents who had monthly income of USD 300 and above were more likely to develop MetS $(p=0.001)$ and elevated BP $(\mathrm{p}=0.003)$ compared to those who earned monthly income below USD 300. Similarly, female respondents who had monthly income of USD 300 and above were more likely to develop MetS $(\mathrm{p}=0.004)$ compared to those with monthly income below USD 300. Overall, respondents with average monthly income of USD 300 and above were more likely to develop MetS $(\mathrm{p}<0.001)$, elevated BP $(p=0.001)$ and raised TGs $(p=0.009)$ than those who earned monthly income below USD 300 (Table 9).

\subsection{Relationship Between Perceived Stress and Metabolic Syndrome-Related Components Among the Respondents}

Of the study respondents, approximately half, (50.5\%), reported having stress. Of those who had stress, a majority (54.4\%), reported the main cause of their stress was financial (ongoing financial strain, laid-off business, threat of unemployment). Some, $(39.2 \%)$ reported they were stressed due to social issues including ongoing difficulties in close relationships, divorced or separated from husband/wife/partner and death of spouse/partner/close friend. Few (6.4\%) reported they were stressed because of their own and family members' health issues. Further analysis with a chi-square test of independence revealed that MetS, BP and FBG level were associated with stress. Respondents who reported feeling stressed were more likely to develop MetS $(p=0.002)$, elevated BP $(\mathrm{p}<0.001)$, raised FBG level $(\mathrm{p}=0.012)$ compared to those without (Table 10).

\subsection{Logistic Regression with Risk Factors for Metabolic Syndrome Categorized by Gender}

A logistic regression analysis was performed with or without metabolic syndrome as the dependent variable with the independent variables namely age, marital status, occupation and family income for males and age, family income and education for females being considered. The logistic models were statistically significant, $\mathrm{c} 2=32.675, \mathrm{df}=3$, $\mathrm{p}<0.001$ for males and $\mathrm{c} 2=28.832, \mathrm{df}=3, \mathrm{p}<0.001$ for female respondents. The model explains $34.8 \%$ (Nagelkerke R2) in males and 27.0\% (Nagelkerke R2) in females, the variance in MetS and correctly classifies $89 \%$ of the causes. Thus, with increasing age, males were 1.12 times 


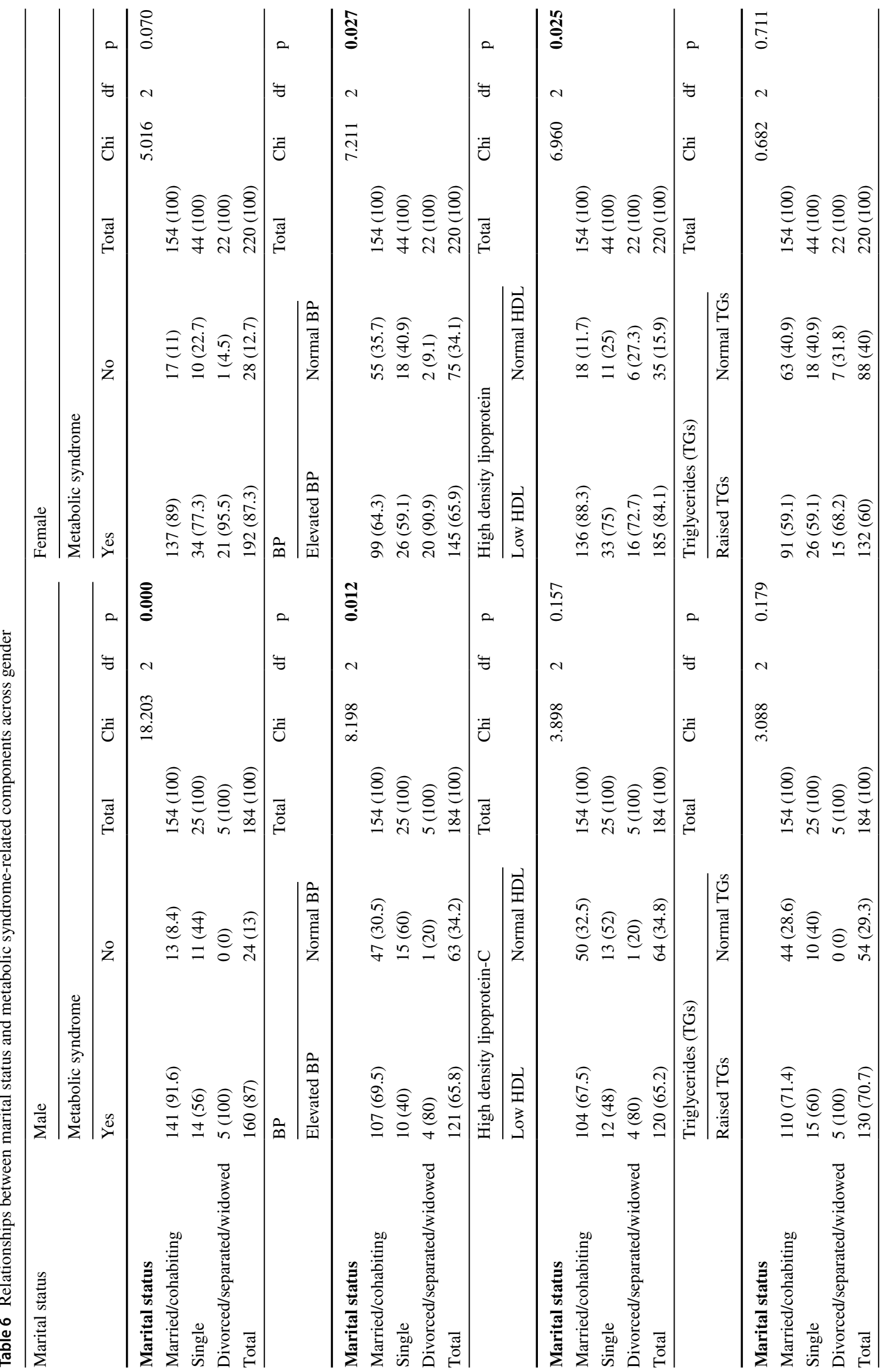


(95\% CI 1.049-1.196, $\mathrm{p}=0.001)$ and females were 1.09 times (95\% CI 1.033-1.156, $\mathrm{p}=0.002)$ likely to develop metabolic syndrome. Moreover, male respondents with higher families' monthly income, were 11.9 times (95\% CI 2.542-55.754, $\mathrm{p}=0.002)$, while females were 13 times $(95 \%$ CI $1.595-105.523, \mathrm{p}=0.017$ ), more likely to develop the metabolic syndrome (Table 11).

\section{Discussion}

Our findings show a high prevalence of metabolic syndrome among adults with central obesity with gender-specific differences in demographic, socio-economic, stress and clini$\mathrm{cal} /$ anthropometric parameters. To the best of our knowledge, this is the first study to determine the prevalence of MetS among adults with central obesity. The high prevalence of MetS in this population is expected because central obesity is closely linked to other components of MetS notably elevated BP, raised fasting blood glucose, triglycerides, and low level of high-density lipoproteins cholesterol. We considered central obesity (waist circumference $\geq 94 \mathrm{~cm}$ for men and $\geq 80 \mathrm{~cm}$ for women) as the first inclusion criteria to screen other components of MetS using the International Diabetes Federation (IDF) criteria. Thus, all the respondents had central obesity. Moreover, of the respondents, $34.2 \%$ and $48.3 \%$ were found to be pre-hypertensive $(\mathrm{BP}=120-139 /$ $80-89 \mathrm{mmHg}$ ) and hypertensive (BP $\geq 140 / 90 \mathrm{mmHg}$ ), respectively. Of the hypertensive respondents, $46.2 \%$, were not aware having hypertension. Additionally, $12.1 \%$ and $11.6 \%$ were pre-diabetic and diabetics, respectively. The study population comprised majorly the low-income earners from the surrounding informal settlements (slums) with an average income of USD 39 per person per month [21]. Another explanation for the higher risks for CVDs among this population could be attributed to environmental stress, psychosocial issues eg poverty, insecurity, violence, and unhealthy dietary pattern associated with large carbohydrates, lack of fruits/vegetables and poor cooking oils [27].

In comparison with international studies, our findings show a higher prevalence of MetS among adults with central obesity compared to other studies. The variation could be differences in approach and the setting of the study. In this study, we screened participants with central obesity as the primary consideration while other studies used a population-based approach. Studies conducted in Europe may show a lower prevalence of MetS compared to LMIC where there is an epidemic of CVDs. For example, in Palestine, the prevalence of MetS was $69.4 \%$ using IDF, while central obesity prevalence among the respondents was $81.3 \%$ [28]. A cross-sectional study conducted among Indian adults found a prevalence of MetS at $76 \%$ (80.4\% in men and $67.8 \%$ in women) using the NCEP: ATP III criteria [29], but all the 
Table 7 Relationship between educational attainment and metabolic syndrome-related components across gender

\begin{tabular}{|c|c|c|c|c|c|c|c|c|c|c|}
\hline \multirow[t]{3}{*}{ Educational status } & \multicolumn{5}{|l|}{ Male } & \multicolumn{5}{|l|}{ Female } \\
\hline & \multicolumn{2}{|c|}{ Metabolic syndrome } & \multirow[t]{2}{*}{ Total } & \multirow[t]{2}{*}{ AOR (95\% CI) } & \multirow[t]{2}{*}{$\mathrm{p}$} & \multicolumn{2}{|c|}{ Metabolic syndrome } & \multirow[t]{2}{*}{ Total } & \multirow[t]{2}{*}{ AOR (95\% CI) } & \multirow[t]{2}{*}{$\mathrm{p}$} \\
\hline & Yes & No & & & & Yes & No & & & \\
\hline None_-primary & $39(92.9)$ & $3(7.1)$ & $42(100)$ & 1 & & $59(88.1)$ & $8(11.9)$ & $67(100)$ & 1 & \\
\hline Secondary & $65(84.4)$ & $12(15.6)$ & 77 (100) & $0.49(0.10-2.43)$ & 0.384 & 98 (91.6) & $9(8.4)$ & $107(100)$ & $0.46(0.16-1.32)$ & 0.149 \\
\hline Tertiary & $57(87.7)$ & $8(12.3)$ & $65(100)$ & $1.28(0.51-3.20)$ & 0.598 & $35(76.1)$ & $11(23.9)$ & $46(100)$ & $0.34(0.14-0.84)$ & 0.019 \\
\hline \multirow[t]{3}{*}{ Total } & $160(87)$ & $24(13)$ & $184(100)$ & & & $192(87.3)$ & $28(12.7)$ & $220(100)$ & & \\
\hline & \multicolumn{2}{|c|}{ Blood pressure } & \multirow[t]{2}{*}{ Total } & \multirow[t]{2}{*}{ AOR $(95 \%$ CI $)$} & \multirow[t]{2}{*}{$\mathrm{p}$} & \multicolumn{2}{|c|}{ Blood pressure } & Total & AOR (95\% CI) & $\mathrm{p}$ \\
\hline & Elevated & Normal & & & & Elevated & Normal & & & \\
\hline None-primary & $21(50.0)$ & $21(50.0)$ & $42(100)$ & 1 & & $35(52.2)$ & $32(47.8)$ & $67(100)$ & 1 & \\
\hline Secondary & $55(71.4)$ & $22(28.6)$ & $77(100)$ & $1.18(0.59-2.39)$ & 0.647 & $80(74.8)$ & $27(25.2)$ & $107(100)$ & $2.62(0.61-10.30$ & 0.021 \\
\hline Tertiary & $44(67.7)$ & $21(32.3)$ & $65(100)$ & $1.08(0.61-1.92)$ & 0.721 & $27(58.7)$ & $19(41.3)$ & $46(100)$ & $1.25(0.55-2.86)$ & 0.081 \\
\hline \multirow[t]{3}{*}{ Total } & $120(65.2)$ & $64(34.9)$ & $184(100)$ & & & $142(64.5)$ & $78(35.5)$ & $220(100)$ & & \\
\hline & \multicolumn{2}{|l|}{ HDL-C } & \multirow[t]{2}{*}{ Total } & \multirow[t]{2}{*}{ AOR (95\% CI) } & \multirow[t]{2}{*}{$\mathrm{p}$} & \multicolumn{2}{|l|}{ HDL-C } & Total & AOR $(95 \%$ CI $)$ & $\mathrm{p}$ \\
\hline & Reduced & Normal & & & & Reduced & Normal & & & \\
\hline None-primary & $27(64.3)$ & $15(35.7)$ & $42(100)$ & 1 & & $28(41.8)$ & $39(58.2)$ & $67(100)$ & 1 & \\
\hline Secondary & $49(63.6)$ & $28(36.4)$ & 77 (100) & $0.88(0.44-1.77)$ & & $57(53.3)$ & $50(46.7)$ & $107(100)$ & $1.21(0.47-3.15)$ & 0.186 \\
\hline Tertiary & $44(67.7)$ & $21(32.3)$ & $65(100)$ & $0.71(0.38-1.31)$ & 0.089 & $21(45.7)$ & $25(54.3)$ & $46(100)$ & $0.75(0.34-1.68)$ & 0.787 \\
\hline \multirow[t]{3}{*}{ Total } & $120(65.2)$ & $64(34.8)$ & $184(100)$ & & 0.097 & $106(48.2)$ & $114(51.8)$ & $220(100)$ & & \\
\hline & \multicolumn{2}{|c|}{ Triglycerides } & \multirow[t]{2}{*}{ Total } & \multirow[t]{2}{*}{ AOR $(95 \%$ CI $)$} & \multirow[t]{2}{*}{$\mathrm{p}$} & Triglycerid & & & AOR (95\% CI) & $\mathrm{p}$ \\
\hline & Raised & Normal & & & & Raised & Normal & & & \\
\hline None_primary & $26(61.9)$ & $16(30.1)$ & $42(100)$ & 1 & & $37(55.2)$ & $30(44.8)$ & $67(100)$ & 1 & \\
\hline Secondary & $52(67.5)$ & $25(32.5)$ & 77 (100) & $1.02(0.50-2.12)$ & 0.176 & $61(57.0)$ & $46(43.0)$ & $107(100)$ & $1.02(0.50-2.12)$ & \\
\hline Tertiary & $51(78.5)$ & $14(21.5)$ & $65(100)$ & $1.92(1.11-3.31)$ & 0.046 & $33(71.7)$ & $13(28.3)$ & $46(100)$ & $1.52(1.11-3.31)$ & 0.073 \\
\hline Total & $129(70.1)$ & $55(29.9)$ & $184(100)$ & & & $131(59.5)$ & $89(40.5)$ & $220(100)$ & & \\
\hline & FBG & & Total & AOR $(95 \% \mathrm{CI})$ & $\mathrm{p}$ & FBG & & Total & AOR (95\% CI) & $\mathrm{p}$ \\
\hline & Raised & Normal & & & & Raised & Normal & & & \\
\hline None_-primary & $6(14.3)$ & $36(85.7)$ & $42(100)$ & 1 & & $18(26.9)$ & $49(73.1)$ & $67(100)$ & 1 & \\
\hline Secondary & $18(23.4)$ & $59(76.6)$ & 77 (100) & $1.02(0.38-2.71)$ & 0.787 & $28(26.2)$ & $79(73.8)$ & $107(100)$ & $1.08(0.61-1.92)$ & \\
\hline Tertiary & $12(18.5)$ & $53(81.5)$ & $65(100)$ & $0.88(0.44-1.77)$ & & $6(13.0)$ & $40(87.0)$ & $46(100)$ & $0.33(0.23-1.96)$ & 0.016 \\
\hline Total & 36 (19.6) & $148(80.4)$ & $184(100)$ & & & $52(23.6)$ & $168(76.4)$ & $220(100)$ & & \\
\hline
\end{tabular}

respondents did not have central obesity. Ten large cohort studies from seven different countries in Europe found a prevalence of MetS ranging from 42.7 to $78.2 \%$, however, the prevalence of obesity was $17.2 \%$ [30]. A study conducted among Brazilian adults found a prevalence of $66.8 \%$ of MetS in men [29], while Salas et al. [31] found the prevalence of MetS at $73.8 \%$ (70.3\% men; $76.0 \%$ women) among obese Mexican adults; however, obesity was determined using BMI rather than waist circumference, as central obesity is the major risk factor for MetS. In our study, all the respondents had central obesity; the principal causative factor in the development of MetS [32, 33]. Additionally, in comparison to the Mexican adolescents, our study respondents were adults (mean age $=42.50$ years) and thus expected to show a higher prevalence of age-related MetS. The key point to be highlighted in our study is that the respondents were a highrisk group than the general population. First, all the respondents had central obesity, unlike the aforementioned studies, a major determinant of MetS and its components probably played for the higher prevalence of MetS in our study. Second, above $50 \%$ of them were hypertensive-diabetic patients who were extremely at higher risk to have MetS compared to those without these conditions. Thirdly, all the respondents were attending an outpatient clinic, probably presented with medical conditions that put them at a higher risk for MetS than the general population.

Notable socio-demographics namely age, gender, marital status, level of educational, employment and family income 


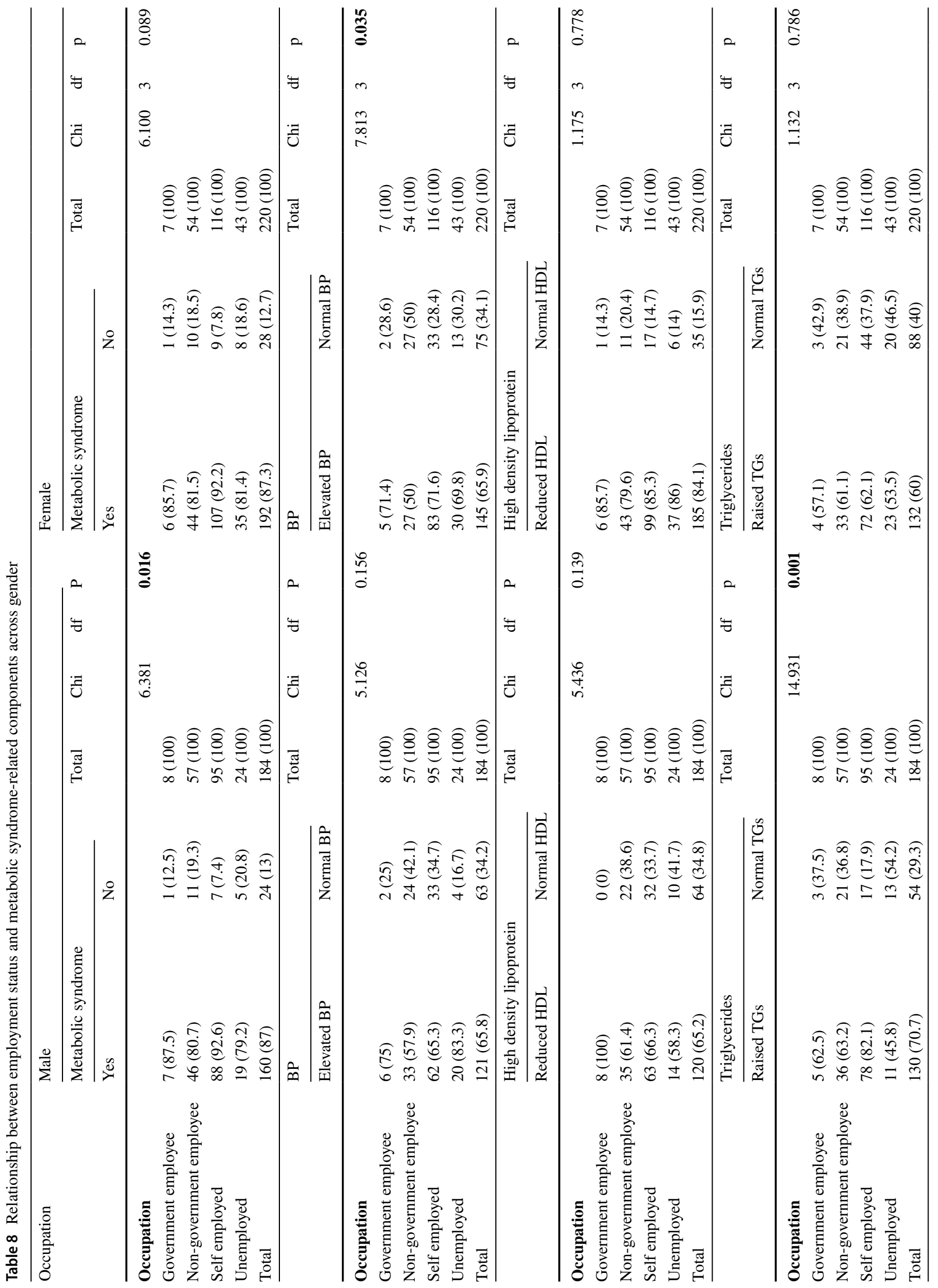




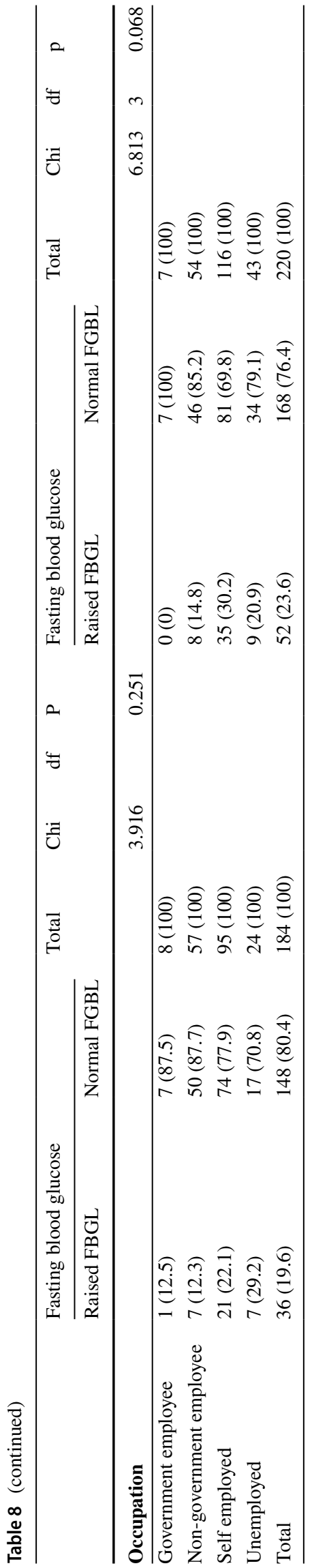

were shown to be important in MetS. Additionally, stress was found to be significantly associated with MetS and related components. This study shows almost half of the clients identified to have hypertension were not aware of their status. The females were more likely to be diagnosed at an earlier age with hypertension (43 for females vs 49 years for males) and diabetes (45 for females vs 52 years for males), respectively. Moreover, females with a family history of hypertension were more likely to have MetS. With regards to the clinical and anthropometric profiles, females were more likely to be known hypertensive, had higher heart rate, body mass index (BMI) and higher risks of CVDs, while males had higher waist circumference. The following narrative expounds on the aforementioned findings.

Advanced age, irrespective of gender, was shown to be associated with a higher prevalence of MetS, evidenced by elevated BP, raised TGs and FBG levels. Advanced age has been linked to lipid/carbohydrate dysmetabolism, atherosclerosis, high blood pressure, some of the classical components of Mets associated with physical, physiological as well as biochemical changes. Notably, the aging process is attributed to changes such as weight gaining, insulin resistance, inflammatory process as well as compromised important compensatory mechanisms notably baroreceptor reflex, kidney's buffering capacity, hardening of blood vessels associated with high BP, diabetes, and MetS [34, 35]. Pathophysiologically, intracellular fat oxidation is an important contributor to insulin resistance associated with aging. This has been linked to inflammation, a key factor in the development of insulin resistance and subsequently type-2 diabetes [36] that is directly related to aging. As regards CVDs, high $\mathrm{BP}$ is directly linked with advanced age due to structural and vasculature changes namely arterial stiffness, baroreceptor reflex and reduction of arterial buffering capacity [37, 38]. A decline in the capacity of the body to process dietary salt resulting in high BP due to aging has been observed. The kidney function and renal blood flow are reduced with age, resulting in activation of the renin-angiotensin-aldosterone system (RAAS) leading to sodium and water retention culminating in hypertension [39-41]. Although these mechanisms were not investigated in the study, their role in causing MetS-related elements cannot be underestimated.

Our findings showed females were more likely to have higher BMI, heart rate and higher risk for CVDs, whereas, males were more likely to have larger waist circumference. Our findings were in line with a study conducted in Nairobi's slums (Korogocho), where, men were more likely to have larger waist circumference, while; women were more likely to have higher BMI [19]. Interestingly, our study shows females with a history of hypertension were more likely to be affected by MetS. This finding implies that CVD-related genetic factors are more pronounced in females in this study population. This elicits the gender differences in markers 


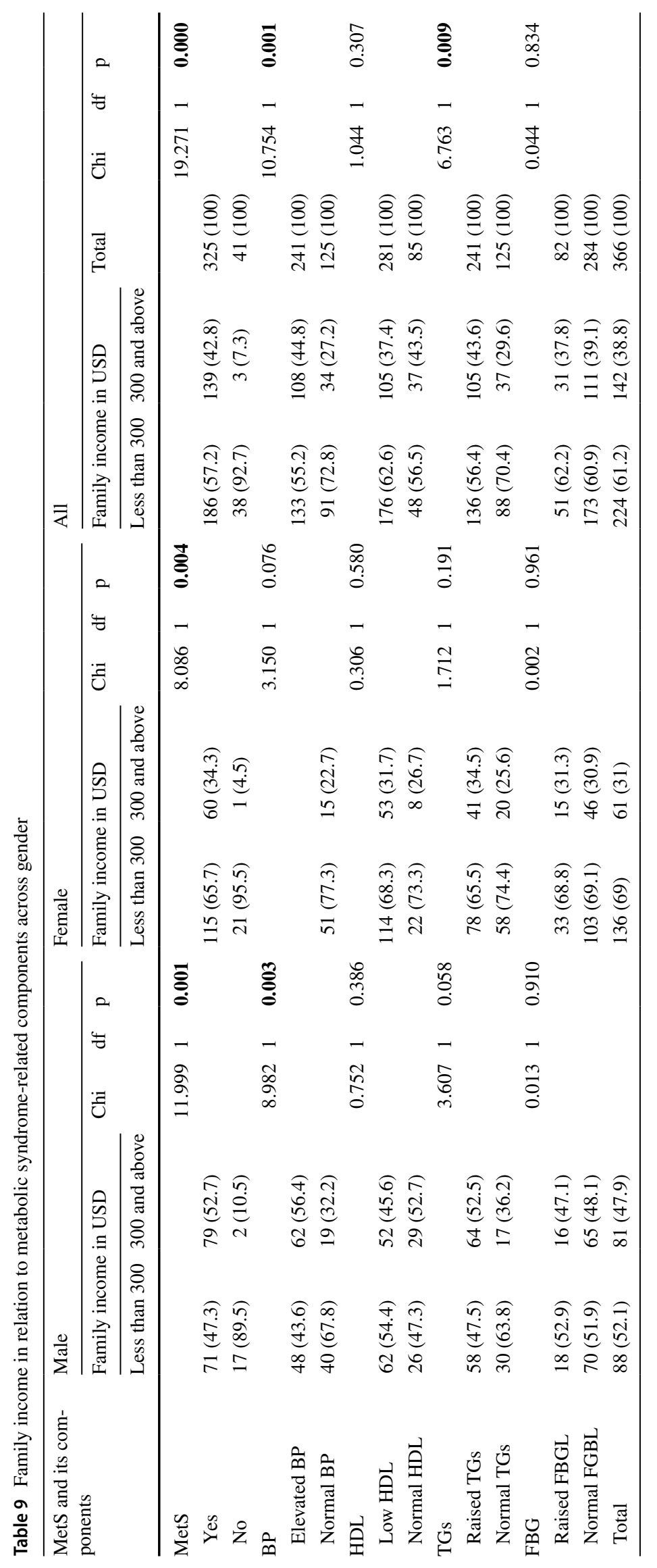


Table 10 Relationship between perceived stress and metabolic syndrome-related components among respondents

\begin{tabular}{|c|c|c|c|c|c|c|}
\hline \multicolumn{2}{|l|}{ Stress } & Male (n, \%) & \multicolumn{2}{|c|}{ Female (n, \%) } & & Total $(\mathrm{n}, \%)$ \\
\hline \multicolumn{2}{|l|}{ Yes } & $87(47.3)$ & \multicolumn{2}{|c|}{$117(53.2)$} & & $204(50.5)$ \\
\hline \multicolumn{2}{|l|}{ No } & $97(52.7)$ & \multicolumn{2}{|c|}{$103(48.8)$} & & $200(49.5)$ \\
\hline \multicolumn{2}{|l|}{ Causes of the stress } & $(\mathrm{n}=87)$ & \multicolumn{2}{|c|}{$(\mathrm{n}=117)$} & & \\
\hline \multicolumn{2}{|l|}{ Financial } & $49(56.3)$ & \multicolumn{2}{|c|}{$62(53.0)$} & & $111(54.4)$ \\
\hline Social & & $32(36.8)$ & \multicolumn{2}{|c|}{$48(41.0)$} & & $80(39.2)$ \\
\hline Health issue & & $6(6.9)$ & \multicolumn{2}{|c|}{7 (6.0) } & & $13(6.4)$ \\
\hline Total & & $87(100)$ & \multicolumn{2}{|c|}{$117(100)$} & & $204(100)$ \\
\hline \multirow[t]{2}{*}{ Stress } & \multicolumn{2}{|c|}{ Metabolic syndrome } & \multirow[t]{2}{*}{ Total } & Chi & df & $\mathrm{p}$ \\
\hline & Yes & No & & & & \\
\hline Yes & $191(93.6)$ & $13(6.4)$ & $204(100)$ & 18.203 & 1 & 0.002 \\
\hline No & $161(80.0)$ & $39(20.0)$ & $200(100)$ & & & \\
\hline Total & $352(87.1)$ & $52(12.9)$ & $404(100)$ & & & \\
\hline Stress & Blood pressure & & Total & & & \\
\hline & Elevated BP & Normal BP & & & & \\
\hline Yes & $158(77.5)$ & $46(22.5)$ & $204(100)$ & 8.198 & 1 & 0.000 \\
\hline No & $108(54.0)$ & $92(46.0)$ & $200(100)$ & & & \\
\hline Total & $266(65.8)$ & $138(34.2)$ & $404(100)$ & & & \\
\hline Stress & High density lipo & otein-C & Total & & & \\
\hline & Reduced HDL-C & Normal HDL-C & & & & \\
\hline Yes & $156(76.5)$ & $48(23.5)$ & $204(100)$ & 3.898 & 1 & 0.157 \\
\hline No & $149(74.5)$ & $51(25.5)$ & $200(100)$ & & & \\
\hline Total & $305(75.5)$ & $99(24.5)$ & 404 (100) & & & \\
\hline Stress & Triglycerides ( $\mathrm{T}$ & & Total & & & \\
\hline & Raised TGs & Normal TGs & & & & \\
\hline Yes & $129(63.2)$ & $75(36.8)$ & 204 (100) & 3.088 & 1 & 0.179 \\
\hline No & $133(66.5)$ & $67(33.5)$ & $200(100)$ & & & \\
\hline Total & $262(64.9)$ & $142(35.1)$ & 404 (100) & & & \\
\hline Stress & Fasting blood glu & ose & Total & & & \\
\hline & Raised FBGL & Normal FGBL & & & & \\
\hline Yes & $55(27.0)$ & $149(73.0)$ & $204(100)$ & 12.535 & 1 & 0.012 \\
\hline No & $33(16.5)$ & $167(83.5)$ & $200(100)$ & & & \\
\hline Total & $88(21.8)$ & $316(78.2)$ & $404(100)$ & & & \\
\hline
\end{tabular}

for CVDs. Although the markers are hormone linked, they are precursors for cardiovascular derangement. The cause of these disparities in clinical, physical, biomarkers and the overall CVDs risk profile between men and women could be due to sex differences in gene expression as well as gender (sociocultural practices such as behaviors, environment, lifestyle, nutrition) differences [42]. Indeed, it has been suggested that obesity in women is associated with hormonal differences that dictate fat distribution [43], predisposing them to a higher risk of high BP compared to age-matched obese men [42]. Although the females may be at risk of
CVDs, the males were, however, found to have larger waist circumference compared to females. This could predispose them to the CVDs because abdominal fat is shown to easily be mobilized into the blood vessels leading to type-2 diabetes and heart events compared to hip fat [44-49]. Additionally, while females are protected during pre-menopause by estrogen hormone which tends to increase HDL-C levels, maintenance of vasodilation, thus BP control [50], males are not. However, our findings appeared to dispute this proposal, with findings showing females as more likely to be affected and diagnosed with both hypertension and diabetes at an 
Table 11 Logistic regression with risk factors for metabolic syndrome categorized by gender

\begin{tabular}{|c|c|c|c|c|c|c|c|c|}
\hline \multirow[t]{2}{*}{ Variable } & \multirow[t]{2}{*}{ B } & \multirow[t]{2}{*}{ SE } & \multirow[t]{2}{*}{ Wald } & \multirow[t]{2}{*}{ df } & \multirow[t]{2}{*}{$\mathrm{p}$-value } & \multirow[t]{2}{*}{ OR } & \multicolumn{2}{|l|}{$95 \% \mathrm{CI}$} \\
\hline & & & & & & & Lower & Upper \\
\hline \multicolumn{9}{|l|}{ Male } \\
\hline Age & 0.113 & 0.033 & 11.501 & 1 & 0.001 & 1.120 & 1.049 & 1.196 \\
\hline Marital status & -0.194 & 0.551 & 0.124 & 1 & 0.725 & 0.824 & 0.280 & 2.426 \\
\hline Family income & 2.477 & 0.788 & 9.886 & 1 & 0.002 & 11.905 & 2.542 & 55.754 \\
\hline Constant & -2.752 & 1.546 & 3.166 & 1 & 0.075 & 0.064 & & \\
\hline \multicolumn{9}{|l|}{ Female } \\
\hline Age & 0.089 & 0.029 & 9.546 & 1 & 0.002 & 1.093 & 1.033 & 1.156 \\
\hline Family income & 2.563 & 1.069 & 5.744 & 1 & 0.017 & 12.975 & 1.595 & 105.523 \\
\hline Education & -0.482 & 0.400 & 1.454 & 1 & 0.228 & 0.617 & 0.282 & 1.352 \\
\hline Constant & -0.724 & 1.499 & 0.233 & 1 & 0.629 & 0.485 & & \\
\hline
\end{tabular}

earlier age than the males. These findings are peculiar and need to be investigated as to the early causes of hypertension and diabetes in females in this population. The findings are however consistent in depicting the burden of CVDs on females together with other studies in Kenya [9] as well as other developing and developed countries [8, 45, 51-55], that showed a high prevalence of overweight/obesity among women. Studies from Brazzaville, Cameroon, and Ghana have reported high cardio-metabolic risk in women compared to men [55-57]. Our study shows that reduced HDL-C was more prevalent in women, while in men it was raised TGs. These findings on the abnormal level of biomarkers are consistent with findings from Kenya [7], China [58], Korea [13, 52, 59, 60] and Taiwan [61] where reduced HDL-C was more prevalent in women and raised TGs in men. Sedentary lifestyle, poor diet, and excess weight are common risk factors in women probably contributed to the higher BMI, low HDL-C level, and risk for CVDs compared to the men. With regards to Triglycerides, in young adulthood up to the age of 49 years, men tend to have higher triglyceride levels than women [62]. Larger waist circumference is linked to an increase in visceral abdominal fat (VAT), accompanied by increased free fatty acid concentration leading to hypertriglyceridemia [63].

Marital status was shown as an important predictor of Mets and its related elements especially in men, with those divorced/separated/widowed linked to a higher risk for MetS. This is attributed to the constellation of factors associated with the social events including buildup of stress, nutritional as well as lifestyle behavior like alcoholism, smoking to wade of stress resulting in MetS. These findings are consistent with several studies [64-66]. For example, it is hard for African men to adopt healthy behaviors such as cooking and eating healthy foods in their homes, but instead prefer restaurant prepared meals including processed/fast foods associated with MetS [9]. Men are likely to engage in alcohol and smoking in a way to wade off stress as well as socialization. In contrast, married men who lived with their spouses have better health behavior [67], thus protected from MetS. Indeed, marriage is associated with many health benefits including decreased cardiovascular morbidity and mortality [66] compared to unmarried, separated, divorced or widowed [68]. Moreover, marital relationships buffer stressful events by providing physical, emotional, mental and psycho-social support benefits $[69,70]$, as well as protection against social isolation, enhances positive health behaviors and discourage health-damaging attitudes and behaviors [71]. Lack of marital relationships may cause stress [70, 72], a precursor for MetS. Related to the aforementioned, we found out that stress was significantly associated with MetS-related components. The respondents reported facing several social, economic and health-related stresses, whose role in causing CVDs is well documented [15]. The social stress is associated with psychosocial stressor thus increasing diseases risk [73]. Socio-economic stress has been attributed to CVDs onset and outcomes in terms of mortality and morbidity rising steadily as social status decreases [74, 75]. Our findings also showed that respondents who had stress were more likely to develop MetS, high BP and raised FBG compared to those without. This result is in line with several studies [76-79] that showed stress as a substantial risk factor for MetS and thus CVDs. Stress activates the autonomic nervous system and neuroendocrine directly, resulting in catecholamine release, vagal withdrawal, cortisol secretion and activation of the renin-angiotensin system [15] which are key risk factors for hypertension, diabetes, and MetS.

Of particular interest in our study is that the prevalence of MetS was inversely associated with the level of educational attainment in women, but not in men. Females with a tertiary level of education were less likely to develop MetS compared to those with primary or no formal education. A higher level of education is associated with economic security, positive healthier behaviors, attitudes, knowledge and awareness, healthier working environment and better access to healthcare. This finding concurs with several studies in Kenya [80], Qatar [81], Sweden [82], Portugal [83], 
Lebanon [84] and South Korea [85] which showed lower education level was associated with a higher risk of the MetS in women. Generally, people with a lower level of education are at higher risk of MetS than those who attained higher education [82, 86, 87]. Likewise, Thomas et al. [88] showed that lifetime risk for CVDs was inversely correlated with educational attainment. Particularly, the lower the educational status of females, the less they care about healthcare and hence, the higher the risk of MetS $[89,90]$. The direct relationship between educational status and MetS in males was associated with lifestyle behavior. These findings are consistent with reports that men who showed higher anthropometric measurements as well as likely hood of poor BP control [9]. On the other hand, men in lower socioeconomic strata are more likely to be involved in physically demanding activities, increasing their total energy expenditure, which may protect them from developing obesity and CVDs. Consistently, several studies have reported an association between higher levels of physical activity and lower rates of chronic diseases, including CVDs [91-93].

Related to the aforementioned employment status and income levels were correlated with MetS. Our findings revealed that employed men in particular and those with higher monthly income were more likely to develop MetS, high BP and raised TGs. The findings are consistent with reports $[11,12,94,95]$ that have shown being employed and having a higher socioeconomic status as risk factors for MetS. Likewise, studies in India [19], China [15], and Saudi Arabia [96] showed higher socioeconomic status as a significant risk factor for MetS. For example, Ogden and colleagues [97] showed men with higher income are more likely to be obese and subsequently develop MetS. However, several studies have reported an inverse relationship between income and MetS and CVDs in developed countries [13, 98-100]. Nevertheless, in developing countries, there is a direct relationship between income and Mets [19]. This divergence can be explained by the quality of food consumed and lifestyle by high-income earners in developing countries mainly the unhealthy fatty foods/sugars and sedentary lifestyle, while those in the developed countries buy quality foods/active lifestyle [101].

Finally, we show that the female respondents with a family history of hypertension were more likely to develop MetS. Although extensive evidence has been generated to show this relationship, this is the first study in Kenya to show this association. This could be attributed to the role of genetics and lifestyle or the combination of the two in influencing MetS. Evidence has shown the association of family history as a risk factor for hypertension and MetS [102, 103]. Indeed, family history of hypertension has been implicated in increased central obesity and MetS, premorbid states for both hypertension and diabetes [104,
105]. Family history of hypertension increases susceptibility to the CVDs because of heritable genetic, environmental and lifestyle behaviors, which are mostly shared among such families than the general population [106]. Although a lot has been documented on this relationship, it is of interest because of genetic studies and preventive counselling as strategies for interventions can be explored.

The study findings should be interpreted in light of some limitations. This is a cross-sectional report of data gathered from baseline survey of "community-based lifestyle modification intervention for the management and control of MetS among adults" which is an ongoing randomized controlled trial (RCT), and as such, may not draw inference about the cause-effect relationship. Additionally, this paper is only focusing on socio-demographic factors in relation to MetS, other critically relevant factors notably dietary and behavioral patterns are not covered. Nevertheless, the ongoing RCT is expected to address these limitations and establish strong evidence on the effects of lifestyle on MetS, to inform overall CVDs prevention strategy.

\section{Conclusions}

Although metabolic syndrome has not been comprehensively researched in Kenya, we show its high prevalence linked to gender-specific differences in demographic, socio-economic, stress and clinical/anthropometric factors. Notable factors including age, gender, marital status, level of educational, employment and family income are important predictors of MetS in the studied population. Of importance is stress, that was associated with social, economic and health challenges which was significantly linked to MetS. Surprisingly, about a half of those identified to have hypertension were not aware of their status an issue that need urgent attention. The females were more likely to be diagnosed earlier with hypertension or diabetes evidenced by higher clinical, anthropometric, and biochemical markers than males who had wider waist circumference. Additionally, subjects with family history of hypertension or diabetes were more likely to develop MetS irrespective of gender. These underscore the need to look beyond the behavioral and biological risk factors and focus on nuance of gender-specific differences in addressing MetS and CVDs. Thus, interventions relevant to MetS should incorporate the aforementioned factors during identification, management and prevention strategies for CVDs.

Author Contributions OTO, SK and WM conceptualized and designed the study. OTO acquired the data, carried out the analyses and interpreted the data and drafted the article. SK and WM critically reviewed the article. 
Data Availability The dataset analyzed during the current study is available from the corresponding author on a reasonable request.

\section{Compliance with Ethical Standards}

Conflict of interest The authors declare that they have no conflict of interests.

\section{References}

1. Suzuki T, et al. Metabolic syndrome, endothelial dysfunction, and risk of cardiovascular events: the Northern Manhattan Study (NOMAS). Am Heart J. 2008;156:405-10. https://doi. org/10.1016/j.ahj.2008.02.022.

2. Ford ES, et al. Metabolic syndrome and incident diabetes: current state of the evidence. Diabetes Care. 2008;31:1898-904. https:// doi.org/10.2337/dc08-0423 (PMC 2518368 Freely accessible. PMID 18591398)

3. Benetos A, et al. All cause of cardiovascular mortality using different definitions of the metabolic syndrome. Am J Cardiol. 2008;102:188-91. https://doi.org/10.1016/j.amjca rd.2008.03.037.

4. Grundy SM. Metabolic syndrome pandemic. Arterioscler Thromb Vasc Biol. 2008;28(4):629-36.

5. Kuk JL, Ardern CI. Age and sex differences in the clustering of metabolic syndrome factors: association with mortality risk. Diabetes Care. 2010;33:2457-61.

6. Park E, Kim J. Gender-and age-specific prevalence of metabolic syndrome among Korean adults analysis of the fifth Korean National Health and Nutrition Examination Survey. J Cardiovascular Nurs. 2015;30:256-66.

7. Kaduka LU, Kombe Y, Kenya E, Kuria E, Bore JK, Bukania ZN, Mwangi M. Prevalence of metabolic syndrome among an Urban population in Kenya. Diabetes Care. 2012;35:887-93.

8. Owolabi M, Miranda JJ, Yaria J, Ovbiagele B. Controlling cardiovascular diseases in low and middle income countries by placing proof in pragmatism. BMJGlobal Health. 2016;1:e000105. https://doi.org/10.1136/bmjgh-2016-000105.

9. Kimani S, Mirie W, Chege M, Okube OT, Muniu S. Association of lifestyle modification and pharmacological adherence on blood pressure control among patients with hypertension at Kenyatta National Hospital, Kenya: a cross-sectional study. BMJ Open. 2019;9:e023995. https://doi.org/10.1136/bmjopen-2018023995.

10. Imperial College London. Global burden of metabolic risk factors of chronic diseases. 2012. https://www.imperial.ac.uk/medic ine/globalmetabolics/.

11. Sy RG, Llanes EJB, Reganit PFM, Castillo-Carandang N, Punzalan FER, Sison OT, Khaing NEE, Poulton R, Woodward M, Tai ES. Socio-demographic factors and the prevalence of metabolic syndrome among filipinos from the LIFECARE Cohor. J Atheroscler Thromb. 2014;21:S9-17.

12. Bhanushali CJ, Kumar K, Wutoh AK, Karavatas S, Habib MJ, Daniel M, Lee E. Association between Lifestyle Factors and Metabolic Syndrome among African Americans in the United States. J Nutr Metab. 2013. https://dx.doi.org/10.1155/2013/51647 5(Article ID 516475).

13. Lim H, Nguyen T, Choue R, Wang Y. Socio-demographic disparities in the composition of metabolic syndrome components among adults in South Korea. Diabetes Care. 2012;35:2028-35.

14. Adediran O, Akintunde AA, Edo AE, Opadijo OG, Araoye AM. Impact of Urbanization and gender on fre-quency of metabolic syndrome among native Abuja set-tlers in Nigeria. J Cardiovasc Dis Res. 2012;3:191-6.

15. Zhan Y, Yu J, Chen R, Gao J, Ding R, Fu Y, Zhang L, Hu D. Socioeconomic status and metabolic syndrome in the general population of China: a cross-sectional study. BMC Public Health. 2012;12:921. https://www.biomedcentral. com/1471-2458/12/921.

16. Aekplakorn W, Kessomboon P, Sangthong R, Chariyalat-ersak S, Putwatana P, Inthawong R, Nitiyanant W, Taneepanichskul S. Urban and rural variation in cluster-ing of metabolic syndrome components in the Thai population: results from the fourth National Health Examination Survey 2009. BMC Public Health. 2011;11:854.

17. Mangat C, Goel NK, Walia DK, Agarwal N, Sharma MK, Kaur J, Singh R, Singh G. Metabolic syndrome: a challenging health issue in highly urbanized Union Territory of north India. Diabetol Metab Syndr. 2010;2:19.

18. Tawakol A, Osborne MT, Wang Y, Hammed B, Tung B, Patrich T, Oberfeld B, Ishai A, Shin LM, Nahrendorf M, Warner ET, Wasfy J, Fayad ZA, Koenen K, Ridker PM, Pitman RK, Armstrong KA. Stress-associated neurobiological pathway linking socioeconomic disparities to cardiovascular disease. J Am Coll Cardiol. 2019;73(25):3243-55.

19. Annelieke H, van de Vijver S, Oti SO, Egondi T, Kyobutung C. Profile of people with hypertension in Nairobi's slums: a descriptive study. Glob Health. 2015;11:26. https://doi.org/10.1186/ s12992-015-0112-1.

20. Van de Vijver SJM, Oti SO, Agyemang C, Gomez GB, Kyobutungi C. Prevalence, awareness, treatment and control of hypertension among slumdwellers in Nairobi Kenya. J Hypertens. 2013;31(5):1018-24.

21. Desgroppes A, Taupin S. Kibera: the biggest slum in Africa? Les Cahiers de l'Afriquede l'Est. 2011;44:23-34 (halshs-00751833).

22. World Health Organization Western Pacific Region. International Association for the Study of Obesity, International Obesity Task Force: The Asia-Pacific Perspective: Redefining Obesity and its Treatment. Sydney: Health Communications Australia; 2000.

23. World Health Organization. Physical status: the use and interpretation of Anthropometry. 2010. https://apps.who.int/iris/bitst ream/10665/37003/1/WHO_TRS_854.pdf.

24. Chobanian AV, Bakris GL, Black HR, et al. The Seventh Report of the Joint National Committee on Prevention, detection, evaluation, and treatment of high blood pressure: the JNC 7 report. JAMA. 2003;289:2560-72.

25. Alberti KG, Eckel RH, Grundy SM, Zimmet PZ, Cleeman JI, Donato KA, Fruchart JC, James WP, Loria CM, Smith SC, Jr., et al. Harmonizing the metabolic syndrome: a joint interim statement of the International Diabetes Federation Task Force on Epidemiology and Prevention; National Heart, Lung, and Blood Institute; American Heart Association; World Heart Federation; International Atherosclerosis Society; and International Association for the Study of Obesity. Circulation. 2009;120:1640-45 (PubMed).

26. American Diabetes Association (ADA). Classification and diagnosis of diabetes: standards of medical care in diabetes. Diabetes Care. 2018;41(Suppl. 1):S13-27. https://doi.org/10.2337/ dc18-S002

27. Van de Vijver SJM, Oti SO, Agyemang C, Gomez GB, Kyobutungi C. Prevalence, awareness, treatment and control of hypertension among slum dwellers in Nairobi Kenya. J Hypertens. 2013;31(5):1018-24.

28. Damiri B, Abualsoud MS, Samara AM, Salameh SK. Metabolic syndrome among overweight and obese adults in Palestinian refugee camps. Diabetol Metab Syndr. 2018;10:34.

29. Vatakencherry RJ, Saraswathy L. Prevalence of metabolic syndrome among adults in a teaching hospital in Kochi, 
Central Kerala: a cross-sectional study. J Fam Med Prim Care. 2019;8:2079-83.

30. van Vliet-Ostaptchouk JV, Nuotio ML, Slagter SN, Doiron D, Fischer K, Foco L, Gaye A, Gögele M, Heier M, Hiekkalinna T, Joensuu A, Newby C, Pang C, Partinen E, Reischl E, Schwienbacher C, Tammesoo ML, Swertz MA, Burton P, Ferretti V, Fortier I, Giepmans L, Harris JR, Hillege HL, Holmen J, Jula A, Kootstra-Ros JE, Kvaløy K, Holmen TL, Männistö S, Metspalu A, Midthjell K, Murtagh MJ, Peters A, Pramstaller PP, Saaristo T, Salomaa V, Stolk RP, Uusitupa M, van der Harst P, van der Klauw MM, Waldenberger M, Perola M, Wolffenbuttel BHR. The prevalence of metabolic syndrome andmetabolically healthy obesity in Europe: a collaborative analysis of ten large cohort studies. BMC Endocr Disord. 2014;14:9.

31. Salas R, Bibiloni MdM, Ramos E, Villarreal JZ, Pons A, et al. Metabolic syndrome prevalence among Northern Mexican adult population. PLoS One. 2014;9(8):e105581. https://doi. org/10.1371/journal.pone.0105581.

32. Carr DB, Utzschneider KM, Hull RL, Kodama K, Retzlaff BM, Brunzell JD, et al. Intra-abdominal fat is a major determinant of the National Cholesterol Education Program Adult Treatment Panel III criteria for the metabolic syndrome. Diabetes. 2004;53(8):2087-94.

33. Furukawa TFS, Shimabukuro M, Iwaki M, Yamada Y, Nakajima Y, Nakay-ama O, Makishima M, Matsuda M, Shimomura I. Increased oxidative stress in obesity and its impact on metabolic syndrome. J Clin Invest. 2004;114:1752-61.

34. Guarner-Lans V, Rubio-Ruiz ME, Perez-Torres I, Baños de McCarthy G. Relation of aging and sex hormones to metabolic syndrome and cardiovascular disease. Exp Gerontol. 2011;46:517-23.

35. Banos G, El Hafidi M, Pérez-Torres I, Guarner V. Insulin resistance and the metabolic syndrome. Yao EB. Hauppauge: Nova Biomedical Books; 2009.

36. Wu D, Ren Z, Pae M, Guo W, Cui X, et al. Aging up-regulates expression of inflammatory mediators in mouse adipose tissue. J Immunol. 2007;179:4829-39.

37. Penuela R, Penuela T. Relationship between blood pressure, age, gender, body mass index and short term blood pressure variability in untreated hypertensive patients. J Hypertens. 2015;33(e-Supplement 1).

38. Howlett SE. Effects of aging on the cardiovascular system. In: Fillit HM, Rockwood K, Woodhouse K, editors. Brocklehurst's Textbook of geriatric medicine and gerontology. 7 th ed. New York: WB Saunders; 2010. p. 168-170.

39. Pinto E. Blood pressure and ageing. Postgrad Med J. 2007;83:109-114. https://doi.org/10.1136/pgmj.2006.048371.

40. Gurven M. Does blood pressure inevitably rise with age? Longitudinal evidence among forager-horticulturalists. Hypertension. 2012;60(1):25-33. https://doi.org/10.1161/HYPERTENSI ONAHA.111.189100.

41. Sun Z. Aging. Arterial Stiffness and Hypertension. Hypertension. 2015;65(2):252-6. https://doi.org/10.1161/HYPERTENSI ONAHA.114.03617.

42. Garcia M, Mulvagh SL, Merz CNB, Buring JE, Manson JE. Cardiovascular disease in women clinical perspectives. 2016;118:1273-93. https://doi.org/10.1161/CIRCRESAHA .116.307547.

43. Global adult tobacco survey (GATS). 2020. https://www.tobac cofreekids.org/assets/global/pdfs/en/GATS_Kenya_Fact_Sheet 2014.pdf.

44. Uth C, Pigeon É, Riou M-È, St-Onge J, Arguin H, Couillard E, et al. Fitness, adiposopathy, and adiposity are independent predictors of insulin sensitivityin middle-aged men without diabetes.
J Physiol Biochem. 2016;72(3):435-44. https://doi.org/10.1007/ s13105-016-0488-2.

45. 1lulu MS, Khaza'ai H, Rahmat A, Patimah I, Abed Y. Obesity can predict andpromote systemic inflammation in healthy adults. Int J Cardiol. 2016; 215:318-24. https://doi.org/10.1016/j.ijcar d.2016.04.089.

46. Guarner V, Rubio-Ruiz ME. Low-grade systemic inflammation connects aging, metabolic syndrome and cardiovascular disease. Interdiscip TopGerontol. 2015;40:99-106. https://doi. org/10.1159/000364934.

47. Taverne F, Richard C, Couture P, et al. Abdominal obesity, insulin resistance, metabolic syndrome and cholesterol homeostasis. Pharm Nutr. 2013;1:130-6.

48. Marsland AL, McCaffery JM, Muldoon MF, Manuck SB. Systemicinflammation and the metabolic syndrome among middleagedcommunity volunteers. Metab Clin Exp. 2010;59(12):18018. https://doi.org/10.1016/j.metabol.2010.05.015.

49. Despres JP, Lemieux I, Bergeron J, et al. Abdominal obesity and the metabolic syndrome: contribution to global cardiometabolic risk. Arterioscler Thromb Vasc Biol. 2008;28:1039-49.

50. Giralt D, Domingues-Montanari S, Mendioroz M, Ortega L, Maisterra O, Perea-Gainza M, Delgado P, Rosell A, Montaner J. The gender gap in stroke: a meta-analysis. Acta Neurol Scand. 2012;125:83-90. https://doi.org/10.111 1/j.1600-0404.2011.01514.

51. Alamgir MA, Javid RA, Hameed A, Mustafa I. Gender difference in components of metabolic syndrome among patients of Type 2 diabetes. Pak J Med Sci. 2015;31(4):886-90. https://dx.doi. org/10.12669/pjms.314.6714.

52. Flegal KM, Carroll MD, Kit BK, Ogden CL. Prevalence of obesity and trends in the distribution of body mass index among US adults, 1999-2010. JAMA. 2012;307:491-7. https://doi. org/10.1001/jama.2012.39.

53. Khaw KT, Wareham N, Bingham S, Welch A, Luben R, Day N. Combined impact of health behaviours and mortality in men and women: the EPIC-Norfolk prospective population study. PLoS Med. 2008;5:e12.

54. Bowman TS, Gaziano JM, Buring JE, et al. A prospective study of cigarette smoking and risk of incident hypertension in women. J Am Coll Cardiol. 2007;50:2085-92.

55. Gombet T, Longo-Mbenza B, Ellenga-Mbolla B, Ikama MS, Kimbally-Kaky G, Nkoua JL. Relationship between coronary heart disease, metabolic syndrome, energy expenditure, body composition, kidney function and low-grade inflammation among bank African employees in Brazzaville. Diabetes Metab Syndr Clin Res Rev. 2010;4:197-203.

56. Fezeu L, Balkau B, Kengne AP, Sobngwi E, Mbanya JC. Metabolic syndrome in a sub-Saharan African setting: central obesity may be the key determinant. Atherosclerosis. 2007;193:70-6.

57. Agyemang C. Rural and urban differences in blood pressure and hypertension in Ghana, West Africa. Public Health. 2006;120:525-33.

58. Cheng M, Wang H, Wang Z, et al. Relationship between dietary factors and the number of altered metabolic syndrome components in Chinese adults: a cross-sectional study using data from the China Health and Nutrition Survey. BMJ Open. 2017;7:e014911. https://doi.org/10.1136/bmjopen-2016-01491 1 .

59. Lee S, Ko Y, Kwak C, Yim E-S. Gender differences in metabolic syndrome components among the Korean 66-year-old population with metabolic syndrome. BMC Geriatr. 2016;16:27. https://doi. org/10.1186/s12877-016-0202-9.

60. Akbulut G, Koksal E, Bilici S, Acar Tek N, Yildiran H, Karadag MG, et al. Metabolic syndrome (MS) in elderly: a cross sectional survey. Arch Gerontol Geriatr. 2011;53:e263-e266266. 
61. Huang JH, Li RH, Huang SL, Sia HK, Lee SS, Wang WH, Tang FC. Relationships between different types of physical activity and metabolic syndrome among Taiwanese workers. Sci Rep. 2017;7:13735. https://doi.org/10.1038/s41598-017-13872-5.

62. Carroll MD, Lacher DA, Sorlie PD, et al. Trends in serum lipids and lipoproteins of adults, 1960-2002. JAMA. 2005;294:177381 (abstract).

63. Pradhan AD. Sex differences in the metabolic syndrome: implications for cardiovascular health in women. Clin Chem. 2014;60:44-52.

64. Jung YA, Kang LL, Kim HN, Park HK*, Hwang HS, Park KY. Relationship between marital status and metabolic syndrome in Korean Middle-Aged Women: the Sixth Korea National Health and Nutrition Examination Survey (2013-2014). Korean J Fam Med, 2018;39:307-12.

65. Cho KI, Kim BH, Je HG, Jang JS, Park YH. Gender-specific associations between socioeconomic status and psychological factors and metabolic syndrome in the Korean population: findings from the 2013 Korean National Health and Nutrition Examination Survey. Bio Med Res Int. 2013. https://doi. org/10.1155/2016/3973197.

66. Troxel WM, Matthews KA, Gallo LC, Kuller LH. Marital quality and occurrence of the metabolic syndrome in women. Arch Intern Med. 2005;165:1022-7.

67. Schoenborn CA. Marital status and health: United States, 19992002. Adv Data. 2004;351:1-32.

68. Ben-Shlomo Y, Smith GD, Shipley M, Marmot MG. Magnitude and causes of mortality differences between married and unmarried men. J Epidemiol Commun Health. 1993;47:200-5.

69. Uecker JE. Marriage and mental health among young adults. J Health Soc Behav. 2012;53(1):67-83.

70. Reczek C, Pudrovska T, Carr D, Thomeer MB, Umberson D. Marital histories and heavy alcohol use among older adults. J Health Soc Behav. 2016;57(1):77-96.

71. Lewis MA, Rook KS. Social control in personal relationships: impact on health behaviors and psychological distress. Health Psychol. 1999;18:63-71.

72. Dinescu D, Turkheimer E, Beam CR, et al. Is marriage a buzzkill? A twin study of marital status and alcohol consumption. J Fam Psychol. 2016;30(6):698.

73. Rook KS. Investigatingthepositiveandnegativesidesofpersonalrelationships: through a lens darkly. In: Spitzberg BH, Cupach WR, editors. The dark side of close relationships. Mahwah, NJ: Lawrence Erlbaum Associates Inc.; 1998. p. 369-393.

74. Marmot M. Social determinants of health inequalities. Lancet. 2005;365:1099-104. https://doi.org/10.1016/S0140 -6736(05)71146-6 (Crossref Medline Google Scholar).

75. Wilkinson RG, Marmot M. Social determinants of health: the solid facts, 2nd edn. Copenhagen: World Health Organization. 2003 (Google Scholar).

76. Janczura M, Bochenek G, Nowobilski R,Dropinski J, KotulaHorowitz K, Laskowicz B, et al. The relationship of metabolic syndrome with stress, Coronary Heart Disease and Pulmonary Function-an occupational cohort-based study. PLoS One. 2015;10(8):e0133750. https://doi.org/10.1371/journ al.pone. 0133750 .

77. Hamer M. Psychosocial stress and cardiovascular disease risk: the role of physical activity. Psychosom Med. 2012;74:896903. https://doi.org/10.1097/PSY.0b013e31827457f 4 (PMID:23107839).

78. Tamashiro KL, Sakai RR, Shively CA, Karatsoreos IN, Reagan LP. Chronic stress, metabolism, and metabolic syndrome. Int J Biol Stress. 2011:14(5).

79. Chandola T, Britton A, Brunner E, Hemingway H, Malik M, Kumari M, et al. Work stress and coronary heart disease: what are the mechanisms? Eur Heart J. 2008;29:640-8. https://doi. org/10.1093/eurheartj/ehm584 (PMID:18216031).

80. Kiama CN, Wamicwe JN, Oyugi EO, Obonyo MO, Mungai JG, Roka ZG, Mwangi A. Prevalence and factors associated with metabolic syndrome in an urban population of adults living with HIV in Nairobi. Kenya. Pan Afr Med J. 2018;29:90https://doi. org/10.11604/pamj.2018.29.90.13328.

81. Al-Thani MH, Cheema S, Sheikh J, Mamtani R, Lowenfels AB, Al-Chetachi WF, Almalki BA, Khalifa SAH, Bakri AOH, Maisonneuve P. Prevalence and determinants of metabolic syndrome in Qatar: results from a National Health Survey. BMJ Open. 2016;6:e009514. https://doi.org/10.1136/bmjopen-2015-009514.

82. Tuomilehto KSJPPJGHJ. Educational inequalities in the metabolic syndrome and coronary heart disease among middle-aged men and women. Int J Epidemiol. 2005;34(2):327-34.

83. Santos AC, Ebrahim S, Barros H. Gender, socio-economic status and metabolic syndrome in middle-aged and old adults. BMC Public Health. 2008;8:62. https://doi. org/10.1186/1471-2458-8-62.

84. Ghadieh R, Mosleh JMB, Hayek SA, Merhi1 S, Fares JEH. The relationship between hypovitaminosis $\mathrm{D}$ and metabolic syndrome: a cross-sectional study among employees of a private University in Lebanon. BMC Nutr. 2018;4:36. https://doi. org/10.1186/s40795-018-0243-x.

85. Cho DY, Koo JW. Differences in metabolic syndrome prevalence by employment type and sex. Int J Environ Res Public Health. 2018;15:1798. https://doi.org/10.3390/ijerph15091798.

86. VanWormera JJ, Boucherb JL, Sidebottomc AC, Sillahc A, Knickelbined T. Lifestyle changes and prevention of metabolic syndrome in the Heart of New Ulm Project. Prev Med Rep. 2017;6:242-5.

87. Dégano IR, Marrugat J, Grau M, Salvador-González B, Ramos R, Zamora A, Martí R, Elosua R. The association between education and cardiovascular disease incidence is mediated by hypertension, diabetes, and body mass index. Sci Rep. 2017;7:12370. https://doi.org/10.1038/s41598-017-10775-3

88. Schwenk TL, Kubota Y, et al. Lower education level is associated with higher risk for cardiovascular disease. JAMA Intern Med. 2017 (Jun 12 Adler NE and Glymour M).

89. Myong JP, Kim HR, Jung-Choi K, Baker D, Choi B. Disparities of metabolic syndrome prevalence by age, gender and occupation among Korean adult workers. Ind Health. 2012;50:115-22 (Cross Ref; PubMed).

90. Park MJ, Yun KE, Lee GE, Cho HJ, Park HS. A cross-sectional study of socioeconomic status and the metabolic syndrome in Korean adults. Ann Epidemiol. 2007;17(4):320-6 (an Abstract).

91. Sattelmair J, Pertman J, Ding EL, Kohl HW III, Haskell W, Lee IM. Dose response between physical activity and risk of coronary heart disease: a meta-analysis. Circulation. 2011;124:789-95. https://doi.org/10.1161/CIRCULATIONAHA.110.010710.

92. Shiroma EJ, Lee IM. Physical activity and cardiovascular health: lessons learned from epidemiological studies across age, gender, and race/ethnicity. Circulation. 2010;122:743-52. https:// doi.org/10.1161/CIRCULATIONAHA.109.914721.

93. Santos AC, Ebrahim S, Barros H. Alcohol intake, smoking, sleeping hours, physical activity and the metabolic syndrome. Prev Med. 2007;44:328-34.

94. Sodjinou R, Agueh V, Fayomi B, Delisle H. Obesity and cardiometabolic risk factors in urban adults of Benin: relationship with socio-economic status, urbanisation, and lifestyle patterns. BMC Public Health. 2008;8:84.

95. Reddy KS, Prabhkaran D, Chaturvedi V, et al. Methods for establishing a surveillance system for cardiovascular diseases in Indian industrial populations. Bull World Health Organ. 2006;84:461-9. https://doi.org/10.1590/S0042-96862006000600015. 
96. Mabry RM, Reeves MM, Eakin EG, Owen N. Gender differences in prevalence of the metabolic syndrome in Gulf Cooperation Council Countries: a systematic review. Diabet Med. 2010;27:593-7.

97. Ogden CL, Lamb MM, Carroll MD, Flegal KM. Obesity and socioeconomic status in adults: United States, 2005-2008. NCHS Data Brief. 2010; 50:1-8 (view at Google Scholar; View at Scopus).

98. Mackenbach JP, Stirbu I, Roskam AJ, Schaap MM, Menvielle $\mathrm{G}$, Leinsalu M, et al. Socioeconomic inequalities in health in 22 European countries. N Engl J Med. 2008;358:2468-81 (PubMed; Google Scholar).

99. Perel P, Langenberg C, Ferrie J, et al. Household wealth and the metabolic syndrome in the Whitehall II study. Diabetes Care. 2006;29:2694-700. https://doi.org/10.2337/dc06-0022.

100. Dallongeville J, Cottel D, Ferrieres J, et al. Household income is associated with the risk of metabolic syndrome in a sex-specific manner. Diabetes Care. 2005;28:409-15. https://doi.org/10.2337/ diacare.28.2.409.

101. Micklesfield LK, Lambert EV, Hume DJ, et al. Socio-cultural, environmental and behavioural determinants of obesity in black South African women. Cardiovasc J Afr. 2013;24:369-75.

102. Ranasinghe P, Cooray DN, Jayawardena R, Katulanda P. The influence of family history of Hypertension on disease prevalence and associated metabolic risk factors among Sri Lankan adults. Ranasinghe et al. BMC Public Health. 2015;15:576.

103. Wang NY, Young JH, Meoni LA, Ford DE, Erlinger TP, Klag MJ. Blood pressure change and risk of hypertension associated with parental hypertension: the Johns Hopkins Precursors Study. Arch Intern Med. 2008;168(6):643-8.

104. Wada K, Tamakoshi K, Yatsuya H, Otsuka R, Murata C, Zhang $\mathrm{H}$, et al. Association between parental histories of hypertension, diabetes. BMC Public Health. 2015;15:576.

105. Liu J, Sekine M, Tatsuse T, Hamanishi S, Fujimura Y, Zheng $\mathrm{X}$. Family history of hypertension and the risk of overweight in Japanese children: results from the Toyama Birth Cohort Study. J Epidemiol. 2014;24(4):304-11.

106. Khanna N, Sharma RS, Sidhu RS. A study of the basic and derived anthropometric indices among the healthy adults (20-30 years of age) of amritsar city (punjab) having family history of hypertension. Int J Biol Med Res. 2011;2(3):743-6.

107. Espósito RC, de Medeiros PJ, de Souza Silva F, Oliveira AG, Aragão CFS, Rocha HAO, Moreira SA, de Farias Sales VS. Prevalence of the metabolic syndrome according to different criteria in the male population during the Blue November Campaign in Natal, RN, Northeastern Brazil. Diabetes Metab Syndr Obes Targets Therapy. 2018;11:401-8. 